\title{
Biological Contamination Prevention for Outer Solar System Moons of Astrobiological Interest: What Do We Need to Know?
}

\author{
Petra Rettberg, ${ }_{1}^{1}$ André Antunes, ${ }^{2}$ John Brucato, ${ }^{3}$ Patricia Cabezas, ${ }^{4}$ Geoffrey Collins, ${ }^{5}$ Alissa Haddaji, ${ }^{6}$ \\ Gerhard Kminek, ${ }^{6}$ Stefan Leuko, ${ }^{1}$ Susan McKenna-Lawlor, ${ }^{7}$ Christine Moissl-Eichinger, ${ }^{8}$ Jean-Louis Fellous, ${ }^{5}$ \\ Karen Olsson-Francis, ${ }^{9}$ David Pearce, ${ }^{10}$ Elke Rabbow, ${ }^{1}$ Samuel Royle, ${ }^{11}$ Mark Saunders, ${ }^{12}$ Mark Sephton, ${ }^{11}$ \\ Andy Spry, ${ }^{13}$ Nicolas Walter, ${ }^{4}$ Robert Wimmer Schweingruber, ${ }^{14}$ and Jean-Charles Treuet $^{15}$
}

\section{Abstract}

To ensure that scientific investments in space exploration are not compromised by terrestrial contamination of celestial bodies, special care needs to be taken to preserve planetary conditions for future astrobiological exploration. Significant effort has been made and is being taken to address planetary protection in the context of inner Solar System exploration. In particular for missions to Mars, detailed internationally accepted guidelines have been established. For missions to the icy moons in the outer Solar System, Europa and Enceladus, the planetary protection requirements are so far based on a probabilistic approach and a conservative estimate of poorly known parameters. One objective of the European Commission-funded project, Planetary Protection of Outer Solar System, was to assess the existing planetary protection approach, to identify inherent knowledge gaps, and to recommend scientific investigations necessary to update the requirements for missions to the icy moons. Key Words: Icy moons-Europa-Enceladus-Planetary protection-Requirements—Spacecraft. Astrobiology 19, 951-974.

\section{Preface}

$\mathbf{P}$ LANETARY PROTECTION IS AIMED to control contamination between Earth and other bodies in the context of space exploration missions. To ensure that scientific investment in space exploration is not compromised by terrestrial contamination, special care needs to be taken by all actors and stakeholders. Committee on Space Research (COSPAR)'s current recommendations are mainly focused on requirements for space missions to Mars. The requirements for missions to the outer Solar System are currently based on quantitative probability of contamination constraints-similar to requirements applicable for missions to Mars several decades ago before easier to implement quantitative bioburden control requirements have been issued.

With increasing evidence for the presence of liquid water in the outer Solar System, the accepted number of potentially habitable environments has increased, and, in consequence,

\footnotetext{
${ }^{1}$ Research Group Astrobiology, Radiation Biology Department, German Aerospace Center (DLR), Institute of Aerospace Medicine, Köln, Germany.

${ }^{2}$ GEMM - Group for Extreme and Marine Microbiology, Department of Biology, Edge Hill University, Ormskirk, United Kingdom.

${ }^{3}$ Department of Physics and Astronomy, Astrophysical Observatory of Arcetri, National Institute for Astrophysics (INAF), Florence, Italy.

${ }^{4}$ Science Connect-European Science Foundation (ESF), Strasbourg, France.

${ }^{5}$ Department of Physics and Astronomy, Wheaton College, Massachusetts, Norton, Massachusetts.

${ }^{6}$ Committee on Space Research (COSPAR), Montpellier, France.

${ }^{7}$ Space Technology Ireland Ltd., Maynooth, Ireleand.

${ }^{8}$ Department of Internal Medicine, Medical University of Graz, Graz, Austria.

${ }^{9}$ Faculty of Science, Technology, Engineering \& Mathematics, School of Environment, Earth \& Ecosystem Sciences, The Open University, Milton Keynes, United Kingdom.

${ }^{10}$ Department of Applied Sciences, Northumbria University, Newcastle, United Kingdom.

${ }_{11}^{11}$ Faculty of Engineering, Department of Earth Science \& Engineering, Imperial College, London, United Kingdom.

${ }^{12}$ Independent Consultant for the US National Academies of Sciences (NAS), Washington, District of Columbia.

${ }_{11}^{13}$ Carl Sagan Center, SETI, Mountain View, California.

${ }^{14}$ Institut für Experimentelle und Angewandte Physik, Abteilung Extraterrestrische Physik, Christian-Albrechts-Universität zu Kiel, Kiel, Germany.

${ }^{15}$ Eurospace, Paris, France.

(C) Petra Rettberg et al., 2019; Published by Mary Ann Liebert, Inc. This Open Access article is distributed under the terms of the Creative Commons License (http://creativecommons.org/licenses/by/4.0), which permits unrestricted use, distribution, and reproduction in any medium, provided the original work is properly credited.
} 
the issue of contaminating other moons and planets is becoming more important and relevant. There are several ongoing missions to planets and small bodies beyond Mars. Space agencies are currently planning missions of astrobiological interest to promising targets such as Ganymede, Enceladus, and Europa. Therefore, updating the COSPAR Planetary Protection Policy is timely and of the utmost importance.

In March 2016, the project "Planetary Protection of the Outer Solar System" (PPOSS) funded by the European Commission's H2020 Programme was kicked off. This project was intended to provide an international platform and forum where various communities (e.g., policy makers, scientific community, and industry) gather and exchange views on the matter of planetary protection with a focus on outer Solar System bodies. Through an intensive 3-year program (2016-2018), the project has nurtured and catalyzed discussions to define strategic science and policy recommendations related to the prevention of biological and organic contamination in the frame of the exploration of the outer Solar System bodies.

The identification of scientific challenges and the assessment of scientific planetary protection requirements are the major focus of the PPOSS project. For this purpose, the PPOSS consortium (Appendix 1) gathered two study groups of international and multidisciplinary experts (see Appendix 2 for the composition of the study groups) to evaluate the current COSPAR Planetary Protection Policy and associated requirements, and to provide new insights and advice. Two different workshops were organized between January and April 2017 in Cologne and Florence, respectively. The discussions and outcome of these workshops as well as additional information, comments, and suggestions obtained from further experts through e-mail exchange and during the 42nd COSPAR Assembly in Pasadena, CA, USA in July 2018 were used as direct inputs into the formulation of the recommendations contained in the present report.

\section{Introduction to Planetary Protection}

From the dawn of space exploration, the international scientific community raised concerns regarding potential lunar and planetary contamination. Indeed, the need to protect celestial bodies was among the earliest space-related policies to be drafted (Tennen, 2004). Planetary protection is an international endeavor to preserve the capability to study planets and moons of astrobiological interest as they exist in their natural state. The contamination with Earth organisms and organic molecules that could be misinterpreted as biosignatures would compromise life detection missions (forward contamination). Moreover, Earth's biosphere needs to be protected from potential harmful extraterrestrial matter carried by a spacecraft returning from an interplanetary mission (backward contamination).

Maintaining and promulgating the COSPAR planetary protection policy and the associated requirements at an international level are under the mandate of COSPAR. In the past, COSPAR's Planetary Protection Policy was mainly focused on planets close to the Sun, in particular Mars, and on their protection from biological contamination. Although the requirements for Mars and the guidelines as to how these may be implemented are based on decades of experience, the necessary measures to study chemical evolution and the potential origin of life in the outer bodies of the Solar System, particularly at Europa and Enceladus, are less developed. Current guidelines are based on conservative estimates of poorly known parameters (Kminek et al., 2017) and given the increased number of planned missions to ever more distant planetary bodies, an updated policy and easier to implement requirements are needed.

To date, the COSPAR Planetary Protection Policy has identified five categories of planetary protection requirements depending on the type of mission, the target body, and the types of scientific investigations involved. For category I missions, no planetary protection measures are necessary, but for category II to $\mathrm{V}$ missions, the planetary protection requirements become increasingly stringent depending on the scientific focus of a particular mission and on the astrobiological relevance of their individual mission target. The COSPAR Planetary Protection Policy lists category specifications for individual target bodies and mission types and assigns different categories to individual icy moon and other outer Solar System bodies in the appendix (Kminek et al., 2017). A short summary is given in Table 1.

\subsection{Planetary protection requirements for Europa and Enceladus}

In addition to the general assignment of target mission types to planetary protection categories, the COSPAR Planetary Protection policy states in its appendix "that requirements for Europa and Enceladus flybys, orbiters and landers, including bioburden reduction, shall be applied in order to reduce the probability of inadvertent contamination of an europan ocean to less than $1 \times 10^{-4}$ per mission." These requirements, based on the Coleman-Sagan formulation of contamination risk, will be refined in future years, but the

\begin{tabular}{|c|c|c|}
\hline Category & Mission type & Target \\
\hline I & $\begin{array}{l}\text { Flyby, orbiter, } \\
\text { lander }\end{array}$ & $\begin{array}{l}\text { Undifferentiated metamorphosed } \\
\text { asteroids; Io; others TBD }\end{array}$ \\
\hline II & $\begin{array}{l}\text { Flyby, orbiter, } \\
\text { lander }\end{array}$ & $\begin{array}{l}\text { Comets; Carbonaceous } \\
\text { Chondrite Asteroids; Jupiter; } \\
\text { Saturn; Uranus; Neptune; } \\
{\text { Ganymede }{ }^{\mathrm{a}} \text {; Callisto; Titan }}^{\mathrm{a}} \text {; } \\
\text { Triton; } \text {; Pluto/Charon }{ }^{\mathrm{a}} \text {; } \\
\text { Ceres; Kuiper Belt Objects } \\
\text { >1/2 the size of Pluto ; Kuiper } \\
\text { Belt Objects }<1 / 2 \text { the size of } \\
\text { Pluto; others TBD }\end{array}$ \\
\hline III & Flyby, orbiters & Europa; Enceladus; others TBD \\
\hline IV & $\begin{array}{l}\text { Lander } \\
\text { missions }\end{array}$ & Europa; Enceladus; others TBD \\
\hline V & $\begin{array}{l}\text { Restricted } \\
\text { Earth return }\end{array}$ & Europa; others TBD \\
\hline
\end{tabular}

aThe mission-specific assignment of these bodies to Category II must be supported by an analysis of the "remote" potential for contamination of the liquid water environments that may exist beneath their surfaces (a probability of introducing a single viable terrestrial organism of $\left.<1 \times 10^{-4}\right)$, addressing both the existence of such environments and the prospects of accessing them.

TBD, to be determined. 
calculation of this probability should include a conservative estimate of poorly known parameters, and address the following factors, at a minimum:

- Bioburden at launch

- Cruise survival for contaminating organisms

- Organism survival in the radiation environment adjacent to Europa or Enceladus

- Probability of landing on Europa or Enceladus

- The mechanisms and timescales of transport to the europan or enceladian subsurface liquid water environment

- Organism survival and proliferation before, during, and after subsurface transfer.

Missions to Enceladus are not explicitly mentioned here, but the same requirements can be assumed to be relevant for Enceladus.

\subsection{Planetary protection requirements for small Solar System bodies}

Small Solar System objects are a very heterogeneous class of objects. Therefore, general planetary protection requirements for those that are not discussed elsewhere in the COSPAR Planetary Protection Policy cannot be formulated but have to be addressed on a case-by-case basis to assign a planetary protection mission category. For Earth return missions, the decision between category $\mathrm{V}$ restricted or unrestricted Earth return has to be based on the answers to the six questions formulated in the policy (Table 2). For containment procedures to be required ("Restricted Earth return"), an answer of "no" or "uncertain" needs to be returned to all six questions.

\subsection{Knowledge gaps}

Our knowledge about the environmental conditions, chemical composition, and geological and mineralogical pro-

Table 2. COSPaR Planetary Protection Policy Questions For the CATEgorization of SAMPle Return Missions From Small Solar System Bodies

1 Does the preponderance of scientific evidence indicate that there was never liquid water in or on the target body?

2 Does the preponderance of scientific evidence indicate that metabolically useful energy sources were never present?

3 Does the preponderance of scientific evidence indicate that there was never sufficient organic matter $\left(\right.$ or $\mathrm{CO}_{2}$ or carbonates and an appropriate source of reducing equivalents) in or on the target body to support life?

4 Does the preponderance of scientific evidence indicate that subsequent to the disappearance of liquid water, the target body has been subjected to extreme temperatures (i.e., $>160^{\circ} \mathrm{C}$ )?

5 Does the preponderance of scientific evidence indicate that there is or was sufficient radiation for biological sterilization of terrestrial life forms?

6 Does the preponderance of scientific evidence indicate that there has been a natural influx to Earth, for example, through meteorites, of material equivalent to a sample returned from the target body?

COSPAR, Committee on Space Research. cesses of the mission targets in the outer Solar System is often very limited. Some of the information necessary for the COSPAR Planetary Protection implementation measures for icy moons and other outer Solar System bodies can only be obtained by future space missions and research projects. The duration of such research activities as well as the associated issues of planning uncertainties in terms of schedule, cost, and acceptance go beyond the scope of a single space project. Mission planners and project experts need more detailed guidance on how to comply with these requirements. The implementation has to be based on traceable, testable, and measurable parameters at comparable levels of confidence.

\subsection{Previous alternative suggestion for PPOSS bodies}

An alternative approach to the current COSPAR Planetary Protection Policy was suggested by the Committee on Planetary Protection Standards for Icy Bodies in the outer Solar System in 2012 in the report "The Assessment of Planetary Requirements for Spacecraft Missions to Icy Solar System Bodies" (Sogin et al., 2012). The committee did not recommend the use of the Coleman-Sagan formulation to estimate the probability of contaminating outer Solar System icy bodies, because this calculation included multiple factors of uncertain magnitude that often lack statistical independence. It suggested instead a series of seven hierarchically organized independent binary decisions that reflect the environmental conditions and geological processes on the target body in the context of metabolic and physiological diversity of terrestrial microorganisms (Table 3). If the answer to at least one of the seven questions would be "no," the entire spacecraft must be

Table 3. Suggested Binary Decision Tree

For ICy Solar System Bodies from the CommitTeE on Planetary Protection Standards For ICy Bodies IN THE OUter Solar System

1 Liquid water: Do current data indicate that the destination lacks liquid water essential for terrestrial life?

2 Key elements: Do current data indicate that the destination lacks any of the key elements (i.e., carbon, hydrogen, nitrogen, phosphorus, sulfur, potassium, magnesium, calcium, oxygen, and iron) required for terrestrial life?

3 Physical conditions: Do current data indicate that the physical properties of the target body are incompatible with known extreme conditions for terrestrial life?

4 Chemical energy: Do current data indicate that the environment lacks an accessible source of chemical energy?

5 Contacting habitable environments: Do current data indicate that the probability of the spacecraft contacting a habitable environment within 1000 years is less than $10^{-4}$ ?

6 Complex nutrients: Do current data indicate that the lack of complex and heterogeneous organic nutrients in aqueous environments will prevent the survival of irradiated and desiccated microbes?

7 Minimal planetary protection: Do current data indicate that heat treatment of the spacecraft at $60^{\circ} \mathrm{C}$ for $5 \mathrm{~h}$ will eliminate all physiological groups that can propagate on the target body? 
subjected to a terminal bioburden reduction process to meet planetary protection guidelines.

\subsection{Different planetary protection challenges for Mars and icy moon missions}

In the past, astrobiological exploration in our Solar System has focused mainly on the planet Mars with potential modern habitable areas to be defined as "special regions." These special regions are areas that may accommodate conditions allowing the survival and replication of terrestrial microorganisms (Rettberg et al., 2015, 2016). The delivery of terrestrial microorganisms to Mars and their subsequent survival and proliferation in these "special regions" can compromise the discovery of pristine evidence of martian life. An environment of biotic relevance, that is, a habitable niche, can have different dimensions from several kilometers to a few micrometers. Different environments, which may be important for present-day life on Mars, have already been documented. These include liquid brines in the near subsurface and impact-related hydrothermal systems, where life could exist if essential elements and an energy source are present (Rummel et al., 2014).

The icy moons in our Solar System are another target of great interest for astrobiology. For some of these icy moons, there is direct evidence for the existence of an ocean underneath the surface, for others there is only indirect evidence. The Cassini mission detected a hydrothermally driven plume from Enceladus (Spencer and Nimmo, 2013; McKay et al., 2014; Hsu et al., 2015). Magnetic field data are best explained by highly conductive saline water below the surface of Europa (Kivelson et al., 2000), Ganymede (Kivelson et al., 2002), and Callisto (Kivelson et al., 2000). The possibility of subsurface water on the icy moons has implications for the origin and distribution of life in the Solar System because liquid water is a key prerequisite for habitability (Sephton, 2004), although the case for an origin of life on the icy moons is under debate (Pascal, 2016).

Numerous flyby and lander missions are being planned to search for life on the moons and the potential of either contaminating indigenous biota or creating false positives in life detection experiments is enhanced by the presence of water. False positive results are generated when a potential terrestrial signal is detected that can be confused with an extraterrestrial signal from biological materials. On Mars, organic compounds are likely to be scarce and the major challenge is their detection. Nonbiological organic compounds can originate from meteoric or cometary material or through synthesis in hydrothermal systems. These organic carbon species can thereafter be transformed through chemical processes that are not very well understood (Mahaffy et al., 2004). The radiation environment of Mars can promote the survival of small organic compounds (Pavlov et al., 2012). On icy moons, organic compounds are likely to be plentiful and the major challenge lies in diagnosing their source. Polymerization of simple organic compounds is favored under icy moon conditions $(\mathrm{Ki}-$ mura and Kitadai, 2015). High radiation environments may produce amino acids and their oligomers, polymers, or macromolecules (Cassidy et al., 2010; Neish et al., 2010; He and Smith, 2014). Likewise, contaminating Earth microorganisms (dead or alive) and their radiation-induced decomposition products can be a source of false positive results in direct life detection or biosignature identification. On Mars, the low abundances of organic compounds can lead to false positives from terrestrial contamination, whereas on icy moons, the detection of polymers and macromolecules can lead to false positives when abiopolymers are confused with biopolymers and are regarded as biosignatures.

To summarize, there are significant differences between Mars and the icy moons, the former is dry and organic matter-poor, whereas the latter are potentially wet and organic matter rich. Contamination on Mars can be expected to comprise local isolated events, even if a transfer of contaminating agents can occur, for example, by dust storms, whereas contamination of subsurface oceans on icy moons can potentially become global. Therefore, planetary protection requirements and contamination prevention measures have to take this into account.

Statement $1 *$ : The recent extension of astrobiological exploration of the outer Solar System from Mars to the icy moons requires reconsideration of the existing planetary protection requirements for icy moons.

\section{Icy Moons}

Moons in the outer Solar System-especially Jupiter's moon Europa and Saturn's moon Enceladus-are promising targets for finding complex organic chemistry and possibly life due to the presence of liquid water under their icy shells. The inner part of the icy moons is presumably formed by a similar rocky core of silicate or metallic rocks-however, the interior structure may vary. The assumed subsurface oceans of the icy moons require an energy source for keeping the water in the liquid state. Unlike Earth's oceans, which are heated from above by sunlight, the subsurface oceans of outer Solar System bodies would be heated from below by the rocky core, and possibly from within by tidal friction (Tyler, 2008). The ice sheet at the surface can form a stagnant or mobile lid allowing convection to a certain degree. The ocean may have a direct contact to the rocky core or to an additional high-pressure ice phase at the bottom. The latter would inhibit the utilization of minerals by life forms.

Common to these icy moons are the low temperatures at the surface and in the subsurface ocean, as well as the negligible atmospheric pressure (with the exception of Titan), resulting in surface conditions far from equilibrium with liquid water. At the surface, water in the form of ice sublimates into vacuum. In some cases, cryovolcanism, as well as geysers, has been observed. The mechanisms and extent of vertical material transport from the subsurface to the surface are controlled by gravity, heat flow, and ice thickness. Vertical transport in the ice shell can be based on top-down or bottom-up processes. Examples for the former are impact gardening, radiation damage, ion implantation, tensile surface fractures, and burial. Bottom-up process can be induced by melting, convection, or fluid-filled cracks. To date, it is not clear whether material exchange in both directions takes

*The statements are numbered in the order they appear in the text. They summarize general findings as well as opinions of the PPOSS team as the basis of the recommendations given in this report. 
place or whether there is an area between the surface and the subsurface, which is not mixed at all.

The temperature of the water in contact with the base of the ice shell is limited to $<0^{\circ} \mathrm{C}$. Any excess energy would induce melting of the ice until a new equilibrium is reached. Heat deposition from below or within, combined with cooling from the top, leads to convective motions within the ocean that will rapidly mix and homogenize the temperature of the ocean to be in equilibrium with the ice shell (Vance and Goodman, 2009). Only if the ocean has a very low salinity and a thin ice shell, the thermal expansion minimum of water can result in the creation of a cold liquid at the top, which would allow for significant (still $<4^{\circ} \mathrm{C}$ ) excursions $>0^{\circ} \mathrm{C}$ in the bulk ocean water (Melosh et al., 2004). Experiments and models scaling hydrothermal plumes on Europa show that even with a large energy input and high water temperature at the seafloor, which once the water is more than $\sim 1 \mathrm{~km}$ from the source, it has mixed with ambient water to lower the temperature anomaly to $\sim 1 \mathrm{mK}$ above the surrounding ocean water (Goodman et al., 2004). Thus, liquid water at temperatures that deviate significantly (tens of degrees) above freezing should only exist in porous channels below the silicate seafloor, or in the immediate vicinity (approximately meters) of a hydrothermal vent at the seafloor.

\subsection{Europa and Enceladus}

Europa is the smallest of the four Galilean moons of Jupiter with a size similar to Earth's moon. It has a young dynamic water ice surface. Beneath the ice, a liquid salty ocean is assumed based on magnetometer measurements and the surface characteristics imaged by remote sensing from the Galileo spacecraft (Khurana et al., 1998, 2008; Pappalardo et al., 1999; Kivelson et al., 2002; Greeley et al., 2004). The surface temperature of Europa is $\sim 80 \mathrm{~K}$ in the polar regions and $\sim 120 \mathrm{~K}$ in the equatorial regions (Spencer et al., 1999). The estimated temperature in the salty ocean is $<0^{\circ} \mathrm{C}$ due to the reduced freezing point of water by dissolved salts. Europa's surface is covered with double ridges, whose exact formation mechanism remains unknown, but is thought to involve tidal cracking of the surface ice and heating from below. Another common feature type is bands formed by separation and spreading of the crust and upwelling of warm ice from below. A significant fraction of Europa's surface is covered by chaotic terrain, where some endogenic heat source has mobilized warm ice and/or shallow liquid water to disrupt pre-existing surface features. The chemical composition of the subsurface ocean is unknown; however, salts such as hydrates of magnesium and sodium sulfates and carbonates have been identified around tectonic features (McCord et al., 2010), but their concentration and the possible presence of additional salts and other chemical compounds are not yet known (Kargel et al., 2000). Thickness estimations of the ice layer are in the range of a few tens of kilometers, for example, at impact crater sites $\sim 15 \mathrm{~km}$ (Schenk and Turtle, 2009). The distance from Europa's surface to the top of the rocky core is assumed to be $80-170 \mathrm{~km}$ (Anderson et al., 1998). Europa has a very thin atmosphere $(0.1 \mu \mathrm{Pa})$ composed of molecular oxygen. Some estimations hint at the possibility that Europa's ocean might be oxygenated (Greenberg, 2010), whereas other models predict a more reduced ocean.

Enceladus is the sixth largest moon of Saturn with a diameter of about $500 \mathrm{~km}$ and an average surface temperature of about
$75 \mathrm{~K}$ with $\sim 33 \mathrm{~K}$ at the north pole and $145 \mathrm{~K}$ at the south pole. The surface has a high albedo and is characterized by several regions of cratered terrain, regions of smooth terrain, and lanes of ridged terrain. In addition, extensive linear cracks and scarps were observed as well as impact craters. A subsurface ocean is assumed to exist beneath the ice layer. Water-rich plumes are emitted near the south pole where the ice thickness is estimated to be $\sim 10 \mathrm{~km}$, indicating local current endogenic geological activities. The ice shell in the equatorial region was modeled to be $>30 \mathrm{~km}$ (Hsu et al., 2015). The distance from the surface of Enceladus to the top of the rocky core is estimated to be $60 \mathrm{~km}$ (Iess et al., 2014). The cryovolcanoes expel geyser-like jets of water vapor and solid material, including sodium chloride crystals, silica and ice particles, carbon dioxide, molecular hydrogen, methane, ammonium, and small quantities of heavier hydrocarbons and other organic molecules (Spencer and Nimmo, 2013; Waite et al., 2017) into space.

\subsection{The radiation environment in the outer Solar System}

The space radiation environment in the outer Solar System is composed of solar particles, mainly electrons, protons, and alpha particles, as well as galactic cosmic rays, which consist nearly exclusively of ions from protons up to uranium. Solar particle events cannot be forecasted, but have the highest probability around solar activity maxima. The Mars Science Laboratory Radiation Assessment Detector (RAD) instrument (Hassler et al., 2012) actively measured the dose rate en route to Mars and found a mean value of 77 micro-Sieverts per hour (Zeitlin et al., 2013). Because of the heliospheric modulation of the predominantly galactic cosmic radiation, this is expected to increase slightly, by $4.5 \% \pm 0.5 \%$ per astronomical units (AU) on the way to the outer planets (Gieseler et al., 2008). The decline in solar activity in the past 3 years has resulted in an increase of the galactic cosmic radiation flux of $\sim 30 \%$ at the Moon (Schwadron et al., 2018). This illustrates the substantial variability of the background radiation field en route to the outer planets. On the surface of Mars, RAD measured a dose rate of 26 micro-Sieverts per hour, but this too has increased by $\sim 50 \%$ in the past 3 years.

Some information is available inside the jovian system, it has been summarized in Paranicas et al. (2007, 2009). The most extreme particle radiation fluxes are seen in the orbital regimes between Io and Europa (Cooper et al., 2001; Jun et al., 2005; Paranicas et al., 2008). This radiation is less intense at Enceladus' orbit around Saturn (Garret et al., 2005). The magnetospheres of Jupiter and Saturn also exhibit high fluxes of energetic electrons that can interact with the surface layers of Europa and Enceladus down to a depth of the order of a meter or so if one also considers their bremsstrahlung photons. Heavy ions induce severe, and difficult to repair, damages in all living organisms (Cucinotta et al., 2017; Moeller et al., 2017). Data regarding the radiation environment on and around Europa from the Voyager and Galileo spacecraft were used to model the depth profile of radiation within the europan ice (Paranicas et al., 2007, 2009). The penetration depth depends on the type and energy of the particle. The derived yearly radiation dose at $1 \mathrm{~m}$ depth was calculated to be $0.3 \mathrm{~Gy} / \mathrm{a}$. Thus, only a few hundred Gray would be accumulated during a stay in that depth of 1000 years, if no transfer or exchange with the 
deeper subsurface occurs. As described in the next paragraph, this radiation dose can be tolerated by many Earth microorganisms.

For the radiation environment of Enceladus, less data are available. However, lower radiation dose rates are expected within the orbit of Enceladus than Europa because the energy and flux of the saturnian magnetospheric electrons are significantly lower than those of jovian magnetospheric electrons.

In addition to ionizing radiation, solar UV radiation is also an important factor in the outer Solar System. The distance between the jovian system and the Sun is 5.2 AU (the distance from Earth to the Sun), leading to a calculated UV irradiance of $\sim 3.7 \%$ of that in low Earth orbit. Although life on Earth is protected by the ozone layer from UV wavelengths shorter than $295 \mathrm{~nm}$, the extremely thin or nonexisting atmospheres of the icy moons are no barrier for those wavelengths. In space and on any celestial body without a significantly UVabsorbing atmosphere, this short wavelength UV radiation reaches the surface. On Mars, wavelengths as low as $200 \mathrm{~nm}$ are transmitted through the $\mathrm{CO}_{2}$ dominated atmosphere of 600-1000 Pa pressure. Owing to their low gravity, the icy moons cannot hold UV filtering atmospheres: Europa's atmosphere is mainly constituted of $\mathrm{O}_{2}$ with pressures $<10^{-6}$ $\mathrm{Pa}$, similar to those of Ganymede and Callisto; Enceladus' trace atmosphere consists mainly of water vapor. Thus, without atmospheric attenuation, the jovian and saturnian systems, which are 5.2 and 9.6 times farther away from the Sun than Earth, experience an irradiance of $3.7 \%$ and $1.1 \%$ of that measured outside Earth's ozone layer.

\section{Life As We Know It}

Even if there is no generally accepted unambiguous definition of life, all life forms on Earth, the only inhabited planet we know, are characterized by certain properties. Organisms are composed of cells, maintain homeostasis, and perform metabolic reactions by exploiting thermodynamic disequilibria for gaining energy from redox reactions. They use compounds from the environment for building up their biomass. They are able to respond to stimuli, adapt to changing environmental conditions, and reproduce and undergo Darwinian evolution. Furthermore, all organisms depend on water as a solvent, for stabilizing the structure of complex molecules and as a partner in biochemical reactions.
Prokaryotic and eukaryotic microorganisms dominate life on Earth with respect to the number of individuals, diversity, and biomass. They are ubiquitous and present in almost all places on Earth, even in "extreme environments," for example, permafrost, glacier ice, hot and cold deserts, salt evaporates, hydrothermal vents, the deep subsurface, hot springs, deep-sea brines, and alkaline and acidic lakes. Microorganisms living in such environments are also known as extremophiles, whereas some are even polyextremophilic, that is, adapted to two or more extreme parameters (Harrison et al., 2013). One example is microorganisms living in deepsea brines where they are exposed to very high salinity (low water activity), high pressure, increased temperature, and high concentrations of heavy metals (Antunes et al. 2011, 2015).

Such environments are called extreme from a human point of view but might not be extreme for the organisms living there. Indeed, such microorganisms do not only survive in such extreme conditions but also require these conditions for metabolism and replication. However, it should be kept in mind that organisms are adapted to their specific habitat, that is, organisms thriving at one end of the parameter range will not grow at the other end. For example, organisms living at very high salt concentrations will not grow at low salt concentrations and those living at high $\mathrm{pH}$ values are not able to live at low $\mathrm{pH}$ values. Our knowledge about the physiological responses of extremophiles to multiple stressors and their ability to replicate under these conditions is very limited (Harrison et al., 2013). It must be noted that in a dormant or anhydrobiosis state, organisms can survive in more "extreme" environments than active metabolizing organisms, which are able to replicate. The ranges for the former are much broader than the latter (Table 4).

\section{Statement 2:}

(a) Microorganisms are ubiquitous and can live in extreme environments.

(b) Organisms are adapted to their specific habitat.

(c) The limits for survival are broader than for replication.

The availability of liquid water is central for life, allowing it to persist and to multiply. Microorganisms that prevail in

Table 4. Limits of Growth and Survival (Modified from Moissl-Eichinger ET aL., 2016)

\begin{tabular}{|c|c|c|}
\hline Environment & Limits of growth & Limits of survival \\
\hline Temperature & $-25^{\circ} \mathrm{C}$ to $+122^{\circ} \mathrm{C}$ & $-263^{\circ} \mathrm{C}$ to $+122^{\circ} \mathrm{C}$ \\
\hline Water stress & $a_{\mathrm{w}} \geq 0.61$ & $0 \leq a_{\mathrm{w}} \leq 1.0$ \\
\hline Low pressure & $0.7 \mathrm{kPa}$ & For example, spores survive vacuum $\left(10^{-6} \mathrm{~Pa}\right)$ \\
\hline Salinity & Up to saturation & Salt crystals (endoevaporites) \\
\hline $\mathrm{pH}$ & $\mathrm{pH}=0-11.5$ & $\mathrm{pH}=0-12.5$ \\
\hline Nutrients & $\begin{array}{l}\text { High metabolic versatility } \\
\text { Lithoautotrophic growth } \\
\text { High starvation tolerance }\end{array}$ & Not required, better without \\
\hline Oxygen & $\begin{array}{l}\text { Anaerobic growth } \\
\text { Aerobic growth, facultative to obligate }\end{array}$ & Not required, better without \\
\hline Radiation & $\begin{array}{l}\text { High UV sensitivity, radiation sensitivity } \\
(<6 \mathrm{kGy},<60 \mathrm{~Gy} / \mathrm{h})\end{array}$ & $\begin{array}{l}\text { Reduced UV and radiation sensitivity at low } \\
\text { temperatures }\end{array}$ \\
\hline Pressure & $100 \mathrm{MPa}(138 \mathrm{MPa}$ in $\mathrm{NaCl})$ & \\
\hline Time & Hours to months & $\leq 25-40 \times 10^{6}$ years \\
\hline
\end{tabular}

w, water activity. 
environments with low water activity are either xerophilic organisms, which have been mostly isolated from preserved food and arid environments, or halophilic, isolated from natural or artificially created hypersaline sites, where water availability is usually limited by high $\mathrm{NaCl}$ concentrations. Xerophiles isolated from high sugar content food are often eukaryotes. Some filamentous fungi can still germinate at values as low as 0.650-0.605 $a_{\mathrm{w}}$ (Stevenson et al., 2015) with calculations further reducing the lower limits to 0.632 and $0.636 a_{\mathrm{w}}$ for Aspergillus penicilloides and Xeromyces bisporus, respectively. Salty environments are usually dominated by prokaryotes, particularly members of the archaea. Haloarchaea are found in environments with $\mathrm{NaCl}$ levels up to saturation and a resulting $a_{\mathrm{w}}$ of 0.75 and were found to survive inside salt crystals or in ancient salt deposits for long time periods (Grant, 2004; Stevenson et al., 2015). Halophilic microorganisms have been shown to grow $<0.7 a_{\mathrm{w}}$, for example, Halococcus salifodinae (0.693), Halobacterium noricense (0.687), Natrinema pallidum (0.681), and haloarchaeal strains GN-2 and GN-5 $\left(0.635 a_{\mathrm{w}}\right)$. Theoretical lower limits of $0.611 a_{\mathrm{w}}$ have been calculated for extremely halophilic archaea and bacteria based on extrapolated growth curves. Collectively, these findings suggest that there is a common water-activity limit that is determined by physicochemical constraints. To cope with the high osmotic stress imposed on the organisms in the low water activity environments, a minority of halophiles use counterbalancing levels of inorganic ions (usually $\mathrm{KCl}$ ); whereas the majority of halophiles, in particular halophilic archaea, and all xerophiles produce or accumulate low-molecular mass organic compounds with osmotic potential (compatible solutes such as trehalose) to achieve osmotic stability.

Vacuum as experienced in space is devoid of any available water. Low pressure of $10^{-3}$ to $10^{-7} \mathrm{~Pa}$ renders active life and metabolism impossible. Nevertheless, a long-term space mission proved that, in an inactive anhydrous state, some microorganisms can survive up to 6 years, and probably longer. In particular, spore formers like bacilli are resistant against the low-pressure vacuum, but also vegetative cells of some species adapted to environments that repeatedly dried in their natural environment can survive space vacuum exposure on space missions or simulated in the laboratory for several months (Table 5) (Billi et al., 2011; Bryce et al., 2015).

In contrast, barophiles or piezophiles are able to survive high pressures. Barophilic organisms have been isolated from deep subsurface areas or oceans. For example, in the laboratory, Shewanella oneidensis remained metabolically active at up to $1000 \mathrm{MPa}$ (Sharma et al., 2002). Interestingly, at that pressure, liquid water should not be available at any temperature.

For microbial life to exist, it also needs an energy source. On Earth, primary production is driven by photosynthesis where energy is gained from the Sun; however, in subsurface environments, where there is no sunlight, primary production is driven by chemotrophs, which gain energy from chemical compounds (Madigan et al., 2009; Oremland et al., 2017). Chemotrophs can harvest energy from reduction-oxidation (redox) reactions using inorganic (lithotrophs) or organic (organotrophs) substrates that are available in the environment. For a review about bacterial redox sensors, please refer to Green and Paget (2004) and references therein. Microorganisms also need a carbon source and some organisms can fix carbon dioxide (called autotrophs); whereas others need an organic carbon source (heterotroph) (Cockell et al., 2016). Virtually all trace organic compounds can support heterotrophic life. Regarding the icy moons, chemoautotrophs are most important, because they can utilize either organic or inorganic compounds, such as iron, hydrogen, or sulfur for metabolism, which are potentially present in the subsurface oceans.

On Earth, the magnetic field effectively shields life from galactic cosmic radiation and heavy ions. In space, and on the icy moon's surface (Paranicas et al., 2007, 2009), microorganisms will be exposed to this high-energy type radiation. Galactic cosmic radiation and HZE (from high $[\mathrm{H}]$ atomic number [Z] and energy [E]) particles cannot be fully shielded by a spacecraft during a long-term space travel. However, a column of water or ice, as expected on the icy moons, reduces the dose effectively to a calculated radiation dose at $1 \mathrm{~m}$ depth of $0.3 \mathrm{~Gy} / \mathrm{a}$ for the Europa moon, providing a possible habitat in the radiation shielded subsurface ocean (Paranicas et al., 2007, 2009). Although radiation on one side is a driver for evolution by mutation induction, on the other side, ionizing radiation is the most deleterious environmental parameter and highly inactivating for microorganisms. The calculated Europa dose rate for ionizing radiation is harmful for most of the higher eukaryotic organisms. A very few radiation-induced DNA double strand breaks per chromosome lead to death in most organisms (Resnick, 1978). Yet, either by evolving cellular mechanisms that protect the proteome and DNA from radiation-induced damage, or by developing highly efficient DNA repair mechanisms, some organisms achieve a high radiation resistance (Pavlopoulou et al., 2016).

Examples of very radiation-resistant organisms are the mesophilic bacterium Deinococcus radiodurans, withstanding radiation doses of up to $5000 \mathrm{~Gy}$ without loss of viability (Moseley, 1983). Also hyperthermophilic archaea such as Thermococcus stetteri, and bacteria such as Ignicoccus hospitalis and Aquifex pyrophilus (Beblo et al., 2011) can tolerate radiation doses up to several thousand Gray comparable with the dose at $1 \mathrm{~m}$ depth on Europa accumulated in about 20,000 years, that is, if no transfer and exchange with the deeper subsurface occur. For Enceladus, less data

Table 5. Examples for Bacterial Survival in Space Vacuum

\begin{tabular}{|c|c|c|c|c|c|}
\hline Mission & Organism & $\begin{array}{c}\text { Duration of } \\
\text { exposure (days) }\end{array}$ & Pressure (Pa) & $\begin{array}{l}\% \text { survival in } \\
\text { thin layers }\end{array}$ & References \\
\hline LDEF & Bacillus subtilis & 2107 & $10^{-6}$ & $1.4 \pm 0.8$ & $\begin{array}{l}\text { Horneck (1993); } \\
\text { Horneck et al. (1994a) }\end{array}$ \\
\hline EURECA & B. subtilis & 327 & $10^{-5}$ & $32.1 \pm 16.3$ & Horneck et al. (1995) \\
\hline EXPOSE-R2 & Deinococcus geothermalis & 672 & $10^{-3}$ to $10^{-4}$ & $0.1 \pm 0.01$ & $\begin{array}{l}\text { Rabbow et al. (2017); } \\
\text { Panitz et al. (in press) }\end{array}$ \\
\hline
\end{tabular}

EURECA, European Retrievable Carriere; LDEF, Long Duration Exposure Facility. 
are available. However, lower radiation dose rates are expected within the orbit of Enceladus at Saturn than Europa. Therefore, the chance of microorganisms surviving on the upper layer of the surface ice of Enceladus is even higher than on Europa. Interestingly, irradiation performed at low temperatures of $-79^{\circ} \mathrm{C}$ even increased the resistance of $D$. radiodurans (Dartnell et al., 2010). Nevertheless, less radiation-resistant microorganisms, for example, Bacillus subtilis, were exposed to galactic cosmic radiation and HZE particles on the long-term missions Exobiology Radiation Assembly on the European Retrievable Carriere (EURECA) and the Long Duration Exposure Facility (LDEF). On EURECA, $25 \%$ of the B. subtilis spores exposed to space radiation of up to $0.41 \mathrm{~Gy}$ for 327 days in vacuum survived (Horneck et al., 1995), whereas on LDEF, still $1 \%$ to $2 \%$ of spores remained viable after a total galactic cosmic radiation of 4.8 Gy experienced in the 2107 day space mission (Horneck et al., 1994a).

The effect of HZE particles on life was investigated on ground utilizing heavy ion accelerators and a variety of microorganisms. Cross sections of the investigated endpoints exhibited a similar dependence on energy as measured in space experiments. For light ions with $Z \leq 4$, they decreased with increasing energy, becoming independent from energy for $Z$ around 10 and finally increasing with energy for ions with $Z \geq 26$ (Baltschukat and Horneck, 1991; Horneck et al., 1994). DNA double strand breaks induced by heavy ions are the most severe DNA damage, leading in most organisms to a disintegration of the DNA that cannot or only insufficiently be repaired. About 100 double strand breaks per chromosome are induced by irradiation with $10,000 \mathrm{~Gy}$ in the mentioned D. radiodurans as shown by pulsed-field gel electrophoresis and successfully repaired within $29 \mathrm{~h}$ without any loss of viability (Daly and Minton, 1996). In a recent series of experiments, different organisms from bacteria, archaea, fungi, lichens, to rotifers were exposed to very high doses of X-rays and HZE particles. The analysis of various biological endpoints with a combination of different biochemical and molecular biological methods, for example, vitality, survivability, cell proliferation, and damage induction, showed a remarkable radiation resistance in many organisms (Moeller et al., 2017, and the references cited therein).

The present-day atmosphere of Earth contains about 21\% oxygen and a stratospheric ozone layer that absorbs the solar UV radiation with wavelengths $<290 \mathrm{~nm}$. However, on the early Earth, when life evolved, the UV climate was different. The atmosphere was anoxic and energy-rich deleterious short wavelength UV radiation could penetrate the atmosphere due to the lack of an ozone layer. In contrast to the penetrating ionizing radiation, UV radiation is only harmful for microorganisms that are not shaded, hence protected, by spacecraft or planetary material or even other microorganisms. Interestingly, the survival of the radiation-resistant $D$. radiodurans is only reduced to $10 \%\left(F_{10}\right)$ after exposure in suspension to $660 \mathrm{Jm}^{-2}$ UVC radiation of $254 \mathrm{~nm}$ and after exposure in a dry form to $1370 \mathrm{Jm}^{-2}$ (Bauermeister et al., 2011). In a similar way, a range of thermophilic microorganisms survived up to $5000 \mathrm{Jm}^{-2}$ monochromatic UVC of $254 \mathrm{~nm}$ (Beblo et al., 2011). The effectiveness of the short UV range $>280 \mathrm{~nm}$ and extraterrestrial UV in killing resistant $B$. subtilis spores was impressively demonstrated in a space experiment performed on Spacelab
D2, where the reduction and loss of the Earth ozone layer were simulated and the biological effectiveness of the resulting solar short UV ranges was determined. Although the measured irradiance increased only slightly, biological effectiveness increased by a factor 1000 (Horneck et al., 1996). An extensive list of ionizing and UV radiation-resistant organisms was reviewed in Gabani and Singh (2013).

Combinations of environmental parameters may act as multiple stressors, adding up to an increase of the total effect. The survivability of high radiation and desiccation resistance bacteria has been attributed not only to effective enzymatic DNA repair mechanisms but also to the protection of proteins from oxidative damage induced by desiccation (Fredrickson et al., 2008; Zhai et al., 2008).

\section{Parameters Influencing the Survival of Earth Organisms with the Potential to Contaminate Icy Moons}

For the planetary protection of icy moons, the only relevant organisms are those with the potential to contaminate the subsurface oceans and replicate ("problematic species") (Box 6). This requires that Earth microorganisms are able to survive different steps over a long period of time under challenging conditions. First, the microorganisms have to enter the clean rooms used for assembly, integration, and testing of space hardware. These are microorganisms that are either associated with humans, originating from the facilities' environment, or brought in with hardware and ground support equipment. For microorganisms, spacecraft assembly clean rooms represent an extreme oligotrophic environment with constant moderate temperature, controlled air circulation, and relatively low and constant humidity. Clean rooms are subjected to strict cleaning regimes with antimicrobial and sporocidal agents (such as ECSS-Q-ST-70-01C; Venkateswaran et al., 2001). Therefore, the replication of microorganisms in clean rooms is not very likely and might be limited to few localized areas within the clean room and to few species of microorganisms, if at all. Only desiccation-resistant vegetative microorganisms or spores, that is, dormant resistant forms of some bacteria, can survive there for a longer period of time.

Clean rooms used for assembly, integration, and testing of spacecraft with planetary protection requirements are biologically monitored on a regular basis. The bioburden and biodiversity in clean rooms are determined following standard procedures and assays (ECSS-Q-ST-70-55C, 2008), in addition to the obligatory bioburden measurements of the spacecraft hardware itself. After rigorous cleaning and bioburden reduction steps, the few microorganisms that remain on the spacecraft hardware alive in a dried form have to survive the transport to the launch site, the integration in the launch vehicle, the launch itself, and the long-term space travel to the final destination in the outer Solar System.

Space travel will take years depending on the mission target and the specific mission schedule. For example, the Juice mission is planned to launch in June 2022 and to arrive in the Jupiter system after 7.6 years in January 2030 (ESA, http:// sci.esa.int/juice/50074-scenario-operations/), whereas Juno traveled in only 4.9 years from Earth to Jupiter (NASA, https:// www.nasa.gov/mission_pages/juno/overview/index.html). In space, the combination of space vacuum, ionizing radiation, extraterrestrial solar UV radiation on the outer surfaces of the 
spacecraft, and low temperatures pose stringent limits on the survival of terrestrial microorganisms.

Whereas most microorganisms can survive low temperatures in a metabolically inactive state, the extremely desiccating conditions induced by exposure to space vacuum inactivate many microorganisms, but not all, for example, spores can survive. After landing, the small percentage of microorganisms that survived until that stage also have to survive on the surface and near surface (i.e., cracks) of the icy moon before being transported to the subsurface ocean. The extent, mechanism, and timescale of the exchange of materials and the potential transport of contaminating organisms between the deeper surface and the subsurface ocean are unknown. Yet, it can be assumed that contaminating organisms would survive for an extended period of time on the very cold surface. If microorganisms were able to penetrate the icy shell and enter the subsurface oceans, the temperatures will be low, that is, $<0^{\circ} \mathrm{C}$, so replication would be limited to psychrophilic/ psychrotolerant microorganisms. It is also unknown whether dissolved minerals and other chemical compounds would be

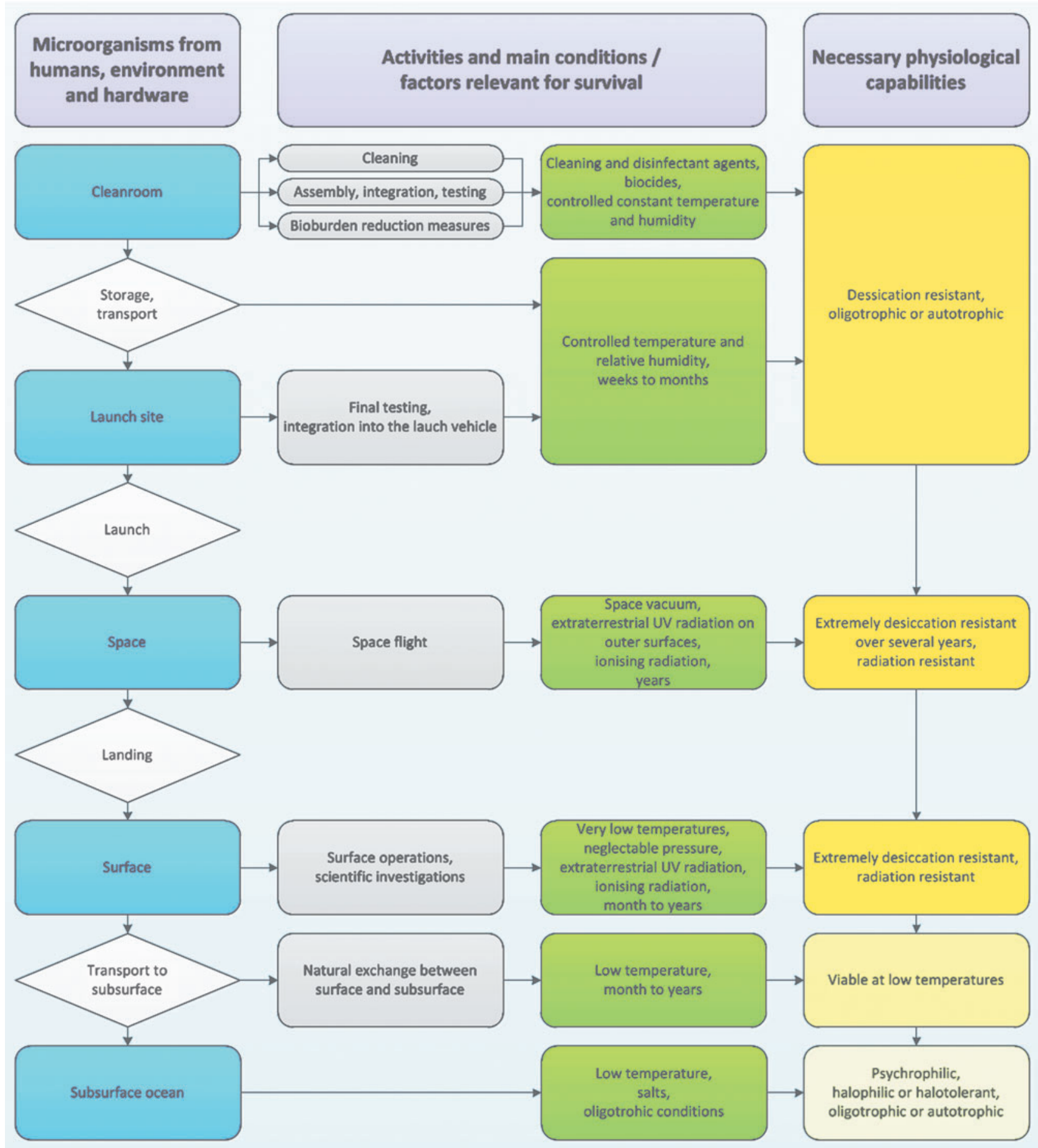

FIG. 1. Microbial characteristics of relevant microorganisms for future missions to the outer Solar System. 


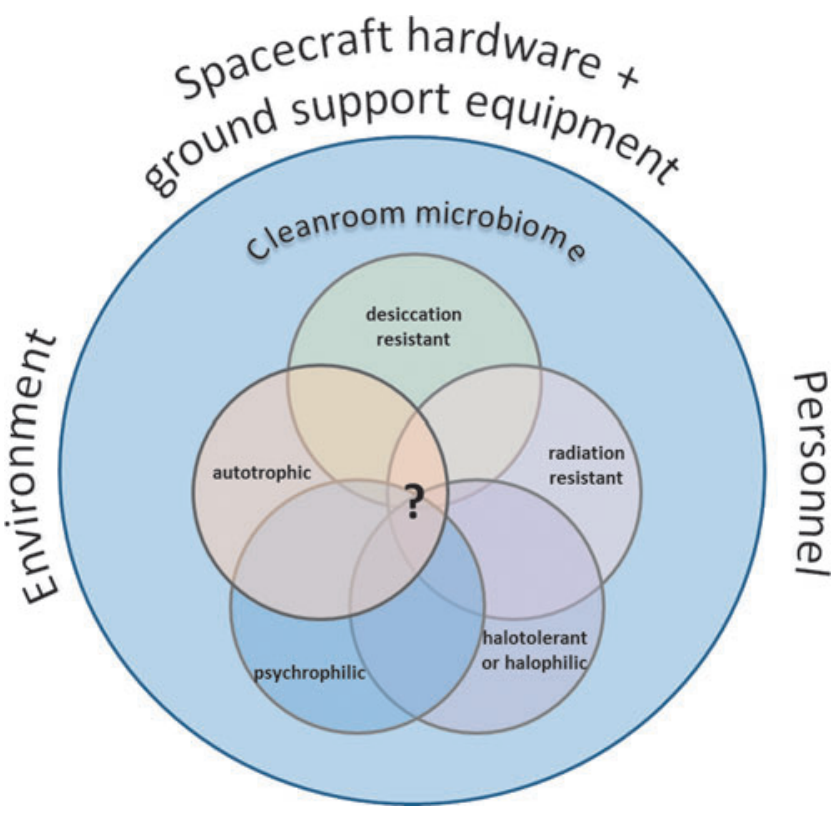

FIG. 2. Relevant organisms with the potential to contaminate icy moons ("problematic species") as a so far unknown subpopulation of the overall clean room microbiome.

available for life. As a consequence, microorganisms are only relevant for icy moons if they are able to survive all of these challenging conditions-from their introduction into the spacecraft assembly clean room to the subsurface ocean of icy moons over several years - and are able to replicate in the subsurface ocean (Figs. 1 and 2). From laboratory experi- ments and field studies, we can derive information about the resistance of organisms to single and multiple icy moon relevant environmental factors, but there are also additional aspects that can influence whether or not an organism can establish itself, grow, and affect the ecology of the environment in which it arrives, in the subsurface ocean of an icy moon. Indeed, in some cases, other organisms or specific conditions might even be a prerequisite. However, these factors are not yet known or understood in sufficient detail.

Statement 3: Relevant organisms with the potential to contaminate icy moons are those that are able to survive long periods (years) of desiccation and vacuum, to survive long periods (years) of exposure to cosmic radiation (during cruise and on the surface of the moons), and to replicate at low temperatures under oligotrophic anoxic conditions in the presence of salts (inside or beneath the ice).

\section{The Present-Day Planetary Protection Approach for Bioburden Determination}

The bioburden limits specified in the COSPAR requirements for different mission type/target combinations are based on results from standardized cultivation assays. In two comparable standards, the detailed procedures for sampling and microbiological analysis of space hardware are described (ECSS-QST-70-55C, 2008; NASA-HDBK-6022, 2010). The sampling technique employed both sterile swabs and wipes moistened with distilled water. Swabs are used for sampling small surfaces up to $25 \mathrm{~cm}^{2}$. Wipes are used preferentially on larger

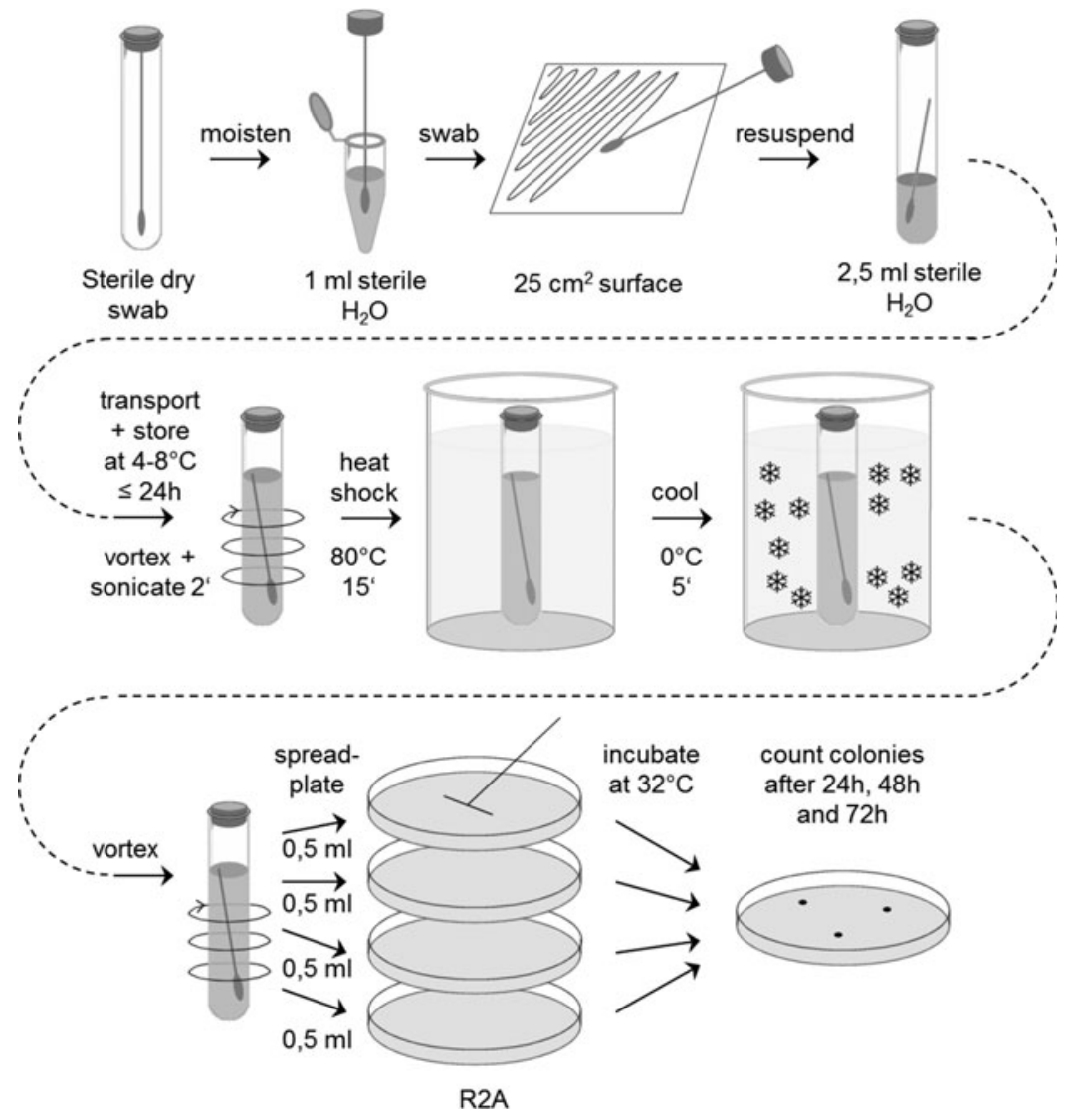

FIG. 3. The ESA bioburden standard assay for swabs (ECSS-Q-ST-70-55C). 
areas up to $1 \mathrm{~m}^{2}$. The microbiological assay procedure features the sonication of the sample with sterile distilled water or rinse solution, followed by an aerobic incubation on nutrient agar (Tryptic Soy agar [TSA] or Reasoner's 2A agar [R2A]) for 3 days at $32^{\circ} \mathrm{C}$. Spore assays are performed by exposing the sample to $80^{\circ} \mathrm{C}$ for $15 \mathrm{~min}$ (Pasteurization step), followed by plating on TSA or R2A agar plates and incubation as already described. The number of colonies (colony-forming units [CFUs]) visible with the naked eye after incubation is used to calculate the overall bioburden of the hardware. An exemplary scheme of a standard planetary protection swab assay is shown in Fig. 3 (ECSS-Q-ST-70-55C). Wipe assays are performed in an analogous way.

With this assay, only mesophilic aerobic spores and bacteria that are able to survive a heat treatment for $15 \mathrm{~min}$ at $80^{\circ} \mathrm{C}$ and that can grow on the specified nutrient medium and conditions are determined. Most of them belong to the genus Bacillus and Paenibacillus. However, also Micrococcus, Staphylococcus, Rothia, Acinetobacter, Stenotrophomonas, and Paracoccus were among the heat-shock-surviving nonspore-forming bacteria (Moissl-Eichinger et al., 2016). The number of microorganisms obtained with this standard assay is used as a proxy for the total number of all microorganisms present in a sample because the majority of them cannot multiply under these conditions. This standard assay is easy to perform, does not need special laboratory equipment, and the results are available after $72 \mathrm{~h}$ of incubation. However, the subset of all organisms that are problematic for PPOSS are not detected by this standard assay.

Statement 4: The ESA/NASA standard assays for bioburden determination do not identify and quantify problematic species.

\section{The Spacecraft Assembly Clean Room Microbiome}

The investigation of the microorganisms in clean rooms and on spacecraft started in the 1960s (for a summary of the history of planetary protection, see Meltzer, 2011). One of the first studies on the microbiome associated with spacecraft hardware was conducted by Puleo et al. (1970a), in which the microbial contamination associated with the Apollo 6 spacecraft was analyzed. In this study, 366 isolates were found and the majority of organisms recovered were indigenous to humans. Since then, many studies focused on the microbiome of clean rooms and the results are discussed hereunder.

Before the rise of molecular techniques, clean rooms and space hardware were routinely investigated by culturedependent methods already described. These methods were employed to calculate the bioburden and investigate the diversity of the Apollo spacecrafts (Puleo et al., 1970b, 1973), the Viking missions (Puelo et al., 1977), and are still the standard techniques to investigate the cultivable microbiome of a clean room or space hardware (Rettberg et al., 2006; NASA-HDBK-6022, 2010). The drawback of this method is that different organisms have different growth requirements (e.g., different temperatures, $\mathrm{pH}$, or nutrient composition) and only a small fraction can be recovered by this method (La Duc et al., 2004a; Stewart, 2012). Another possibility to detect viable bacteria is the use of an adenosine triphosphate (ATP)-based detection system and was first tried in a clean room environment by Venkateswaran et al. (2003a). Because ATP is used by all living organisms, it can be used as an indicator for the presence of living organisms as previously described (Chappelle and Levin, 1968). Although this is a very straightforward assay, the amount of intracellular ATP varies with cell size, species, and physiological state (Venkateswaran et al., 2003a), making it difficult to quantify and compare the results with other techniques such as the CFU detection method. This method has been shown to work well with clean roomassociated organisms such as Bacillus sp. and previous research also suggests that this method is suitable to distinguish between viable and nonviable spores (Rawsthorne et al., 2009; Mohapatra and La Duc, 2012). The same holds true for psychrophilic (Dieser et al., 2010), heat-tolerant, and alkaliphilic organisms (Guo and Zhang, 2014).

With the increase in molecular techniques, researchers were able to elucidate the microbiome of a clean room with greater detail. The first study was presented by La Duc et al. (2003) wherein they describe the microbial characterization of the Mars Odyssey spacecraft and the facility used by the spacecraft by direct $16 \mathrm{~S}$ rRNA amplification without previous culturing. Several studies have been conducted using this method (Moissl et al., 2007a,b; Newcombe et al., 2008; La Duc et al., 2009; Vaishampayan et al., 2010; Stieglmeier et al., 2012), leading to the realization that these environments harbor a diverse set of microorganisms and that even archaea (Moissl et al., 2008) and anaerobic organisms (Probst et al., 2010) are present. Further advances such as pyrosequencing, Phylochip analysis, or next generation sequencing dramatically changed our perception of the microbiome associated with clean rooms and space hardware (La Duc et al., 2012; Zhang et al., 2018).

Although improved sequencing methods increased our understanding of the diversity associated with these environments, one cannot differentiate between living organisms or just the presence of the $16 \mathrm{~S}$ rDNA signature from dead organisms. To address this issue, several studies employed propidium monoazide (PMA), a pre-PCR dye that is able to discriminate live and dead cells (Vaishampayan et al., 2013a; Henrickson et al., 2017). PMA is highly membrane impermeable and generally excluded from cells with an intact membrane assumed to be viable. Upon penetrating compromised cell membranes, PMA binds to DNA by intercalating and upon photoactivation, covalently binds the DNA and, therefore, making it not available for PCR amplification (Nocker et al., 2006). This method has been shown to work well with clean room-associated organisms such as Bacillus sp. and previous research also suggests that this method is suitable to distinguish between viable and nonviable spores (Rawsthorne et al., 2009; Mohapatra and La Duc, 2012). The same holds true for psychrophilic (Dieser et al., 2010), heat-tolerant, and alkaliphilic organisms (Guo and Zhang, 2014). Although this method is promising, it does not work for all organisms. For example, dead or alive halophilic archaea cannot be discriminated because $\mathrm{NaCl}$ inhibits PMA from inhibiting PCR amplification (Barth et al., 2012). Clean rooms are obviously not typical habitats for halophilic archaea, yet molecular studies have found signatures of halophilic archaea in such environments (Moissl-Eichinger, 2011), making it important to keep halophilic archaea in consideration when thinking of possible forward contamination. Fittipaldi et al. (2011) 
evaluated the viable real-time PCR using PMA method for environmental samples. The suggested approach based on the combination of three real-time PCR amplifications for each sample leads to improved viable cell estimations, but cannot exclude false positives completely.

Recommendation $\mathbf{1}^{\dagger}$ : Investigate the applicability of methods for the discrimination of dead and alive cells from problematic species in low-biomass environments.

Several studies have characterized and described isolates from clean room environments and spacecraft, and currently there are nine newly described species and one novel genus: Bacillus nealsonii (Venkateswaran et al., 2003b), Bacillus odysseyi (La Duc et al., 2004b), Paenibacillus pasadenensis, Paenibacillus barengoltzii (Osman et al., 2006), Bacillus safensis (Satomi et al., 2006), Bacillus canaveralius (Newcombe et al., 2009), Paenibacillus purispatii (Behrendt et al., 2010), Bacillus horneckiae (Vaishampayan et al., 2010), Paenibacillus phoenicis sp. nov (Benardini et al., 2011), and the novel genus Tersicoccus phoenicis (Vaishampayan et al., 2013b). Besides these properly described strains, there are several hundred strains deposited at the Deutsche Sammlung von Mikroorganismen und Zellkulturen $\mathrm{GmbH}$, Braunschweig, Germany (Moissl-Eichinger et al., 2012) and the ARS culture collection (Venkateswaran et al., 2014) that await further characterization. Several investigations have been conducted elucidating the resistance of selected isolates against common cleaning procedures such as cleaning with $70 \%$ isopropanol, $5 \%$ hydrogen peroxide, and UV radiation, and some tested strains show increased resistance against these threats than type strains (Link et al., 2004; Kempf et al., 2005; Gosh et al., 2010). However, not all isolates from these environments are resistant against decontamination treatment, even isolates obtained from the same clean room and the same sampling opportunity may differ in their resistance. Kempf et al. (2005) showed that strains of Bacillus pumilus that were isolated during the same sampling campaign from the Jet Propulsion Laboratory-Spacecraft Assembly Facility differ dramatically in their ability to tolerate exposure to $5 \%$ liquid $\mathrm{H}_{2} \mathrm{O}_{2}$ (Kempf et al., 2005).

High Efficiency Particulate Air filtration, humidity and temperature control, partial overpressure (in ISO class 5 clean rooms), frequent cleaning, limited number of persons working at the same time in a clean room, and strict garment changing protocols-all these clean room maintenance procedures have strong impact on the abundance, viability, and diversity of microorganisms therein (Moissl-Eichinger et al., 2015). However, with people working within these facilities, sterility cannot be accomplished. Most of the organisms found in the previously discussed studies were considered indigenous to humans such as Staphylococcus, Micrococcus, and the Corynebacterium-Brevibacterium group (Puleo et al., 1973). The remaining isolates originate from the environment of the spacecraft assembly facility with some of them typical for the individual location and others that are generally associated with soil, dust, or plants (La Duc et al., 2004a;

\footnotetext{
${ }^{\dagger}$ Recommendations are numbered to facilitate referencing. The order does not indicate the importance or timeframe.
}

Rettberg et al., 2006; Moissl-Eichinger et al., 2015). One study by Foster and Winans (1975) recovered psychrophilic microorganisms from surrounding areas where the Viking Spacecraft was assembled. Although psychrophiles were not found within the assembly area, the authors demonstrated that the employed techniques would not have detected these organisms.

The comparison of the microbiome data from different clean rooms in different countries and climate zones using the available published data is difficult, because different analysis methods have been employed. To be truly able to compare the biodiversity of spacecraft assembly facilities and space hardware, all investigations need to follow the same protocol, including the record of metadata with a clear description of the sequencing platforms, bioinformatics tools, and data bases used for analysis. Owing to rapid technological developments in this area, these protocols have to be updated on a regular basis. Reduced sequencing costs, high throughput methods, and powerful new analytical tools, which have been developed in the past few years, enable the investigation of microbial communities in great detail. However, each step from sample collection, storage, DNA extraction, sequencing, and computational and statistical methods for data analysis can induce bias and influence the interpretation of the obtained data as summarized in a recent review from Hugerth and Andersson (2017).

In addition, it is mandatory to establish and maintain an international quality controlled data repository for microbiome data from spacecraft assembly clean rooms and spacecraft. The data base format has to be flexible to allow the implementation of future optimized protocols and handle the enormously increasing data volume.

Recommendation 2: Define a detailed protocol for the molecular analysis of the clean room and spacecraft microbiome, including metadata with detailed information about the sequencing platforms and the bioinformatics tools used for analysis. Update this protocol on a regular basis taking new technological developments into consideration.

Recommendation 3: Establish and maintain an international quality-controlled microbiome data repository for data from spacecraft assembly clean rooms and spacecraft.

In all investigated spacecraft assembly clean rooms, the microbial community was found to be very diverse. Microorganisms belonging to genera with extremotolerant members were found in all clean rooms both with cultivation assays and with molecular methods (La Duc et al., 2007; Moissl-Eichinger et al., 2015). With only knowing the genus of a microorganism, it is not possible to predict the resistance against different environmental factors. Closely related species as well as different bacterial strains from the same species can possess a very distinct physiological potential (Kempf et al., 2005; Callegan et al., 2008; Faglaiarone et al., 2017). So far, insights into the resistance against desiccation, radiation, low temperatures, salts, etc., and combinations of these factors cannot be deduced from the available information about the clean room microbiome. 
Statement 5: With the present-day methods for biodiversity determination, it is not possible to identify and quantify planetary protection-relevant microorganisms for icy moons as defined in statement 3.

\section{Bioburden Reduction by Sterilization}

As already mentioned, the only microorganisms that are problematic for icy moons are those that can reach the subsurface oceans and replicate there. One aspect already addressed in "The Assessment of Planetary Requirements for Spacecraft Missions to Icy Solar System Bodies" (Sogin et al., 2012) is the practice of sterilization of space hardware with dry heat. In the European Cooperation for Space Standardization (ECSS) standard ECSS-Q-ST-70-57C, different combinations of temperatures $>110^{\circ} \mathrm{C}$ and exposure times are specified with a detailed process description. In the report from Sogin et al. (2012), the suggestion was made to lower the sterilization temperature under the assumption that psychrophilic or psychrotolerant organisms can be killed at lower temperatures than mesophilic organisms. The existing literature is not very exhaustive and does not support this assumption in general. Previous research supports the assumption that thermophiles generally produce more resistant spores than do mesophiles, which produce more resistant spores than do psychrophiles (Marquis and Bender, 1985). In addition, Winans et al. reported in 1977 that spores from psychrophilic organisms, isolated from the vicinity of the Viking spacecraft assembly area, are more susceptible to dry heat than mesophilic organisms (Winans et al., 1977). Although research suggests the lower dry heat resistance of certain species, novel psychrophilic organisms have been isolated and identified, where little to nothing is known about their resistance to dry heat. In particular, the previously identified problematic species have not been investigated in this matter. Therefore, the heat resistance of problematic species should be investigated at different temperatures $<110^{\circ} \mathrm{C}$ to find out, if the sterilization temperature for space hardware could be lowered in consequence.

Recommendation 4: Investigate the heat resistance at temperatures $<110^{\circ} \mathrm{C}$ of planetary protection-relevant species for icy moons, in particular, spore formers, using standard sterilization procedures for space hardware.

\section{Mid- and Long-Term Research Activities for the Identification of Relevant Species}

\subsection{Cultivation and stress tests}

Today, the capability of microorganisms to withstand the deleterious environmental factors during a mission to the outer Solar System can only be determined with cultivable organisms, by performing stress tests. Depending on the species, the necessary cultivation time can be long, and take up to weeks and months, before results are available. This is especially the case for psychrophiles, organisms growing at low temperatures $\left(-20^{\circ} \mathrm{C}\right.$ to $+15^{\circ} \mathrm{C}$; Pulschen et al., 2017) or halophiles, organisms growing at high salt concentrations of up to $30 \% \mathrm{NaCl}$ (Pedrós-Alió et al., 2000; Reid et al., 2006; Burns et al., 2007; Schneegurt et al., 2012; Stan-Lotter and Frendrihan, 2015).
Exposure to combined stresses can prolong the necessary incubation period even more. Systematic investigations on this topic are necessary to gain a deeper general understanding of the physiology of the microorganisms in a spacecraft assembly clean room, the composition of the microbial community, and the identification of potentially problematic species.

Statement 6: Although microbial strains from spacecraft assembly clean rooms and spacecraft from ESA missions are deposited in a publicly available culture collection, the majority of microbial strains isolated in the context of missions performed by NASA and other spacefaring nations cannot be obtained for basic research.

Recommendation 5: Establish and maintain an international culture collection for microorganisms from spacecraft and spacecraft assembly clean rooms, including those from non-ESA missions.

To identify microbial species that are problematic for icy moons, a systematic overview of typical microbial clean room inhabitants is necessary.

\section{Recommendation 6:}

(a) Systematically compile the available published data about the extremotolerance of clean room isolates with a focus on desiccation and radiation resistance, halophilic, oligotrophic (autotrophic), psychrophilic, (facultative) anaerobic growth.

(b) Investigate the desiccation and radiation resistance of representative spacecraft assembly clean room isolates, starting with organisms that are already available in culture collections.

(c) Collect new isolates representing a wide range of metabolisms from clean rooms and investigate in the same way as in (b) to get a broader basis for a first estimation of the abundance of problematic species.

(d) Obtain additional new insights into the molecular and cellular stress response mechanisms of potentially problematic species from isolates from recent Earth analog environments for icy moons such as polar regions, subglacial lakes, and deep sea or terrestrial brines. Perform laboratory experiments under subsurface icy moon conditions to assess their potential for survival and replication.

Table 6 gives a preliminary list of bacteria to be investigated. All of them are publicly available from culture collections, for example, the ESA Microbial Collection at the German Collection of Microorganisms and Cell Cultures (DSMZ; https://www.dsmz.de). The current list is conditioned by a series of assumptions and practical considerations based on its focus on planetary protection. It should be seen as a draft, and open to later inclusions, updates, and revisions, depending on input from other experts and advances in our understanding of the microbiology of these locations as well as our knowledge on the environmental conditions on the icy moons of the outer Solar System. The selection criteria are listed in the table: detected in spacecraft assembly clean rooms by cultivation, representing a 


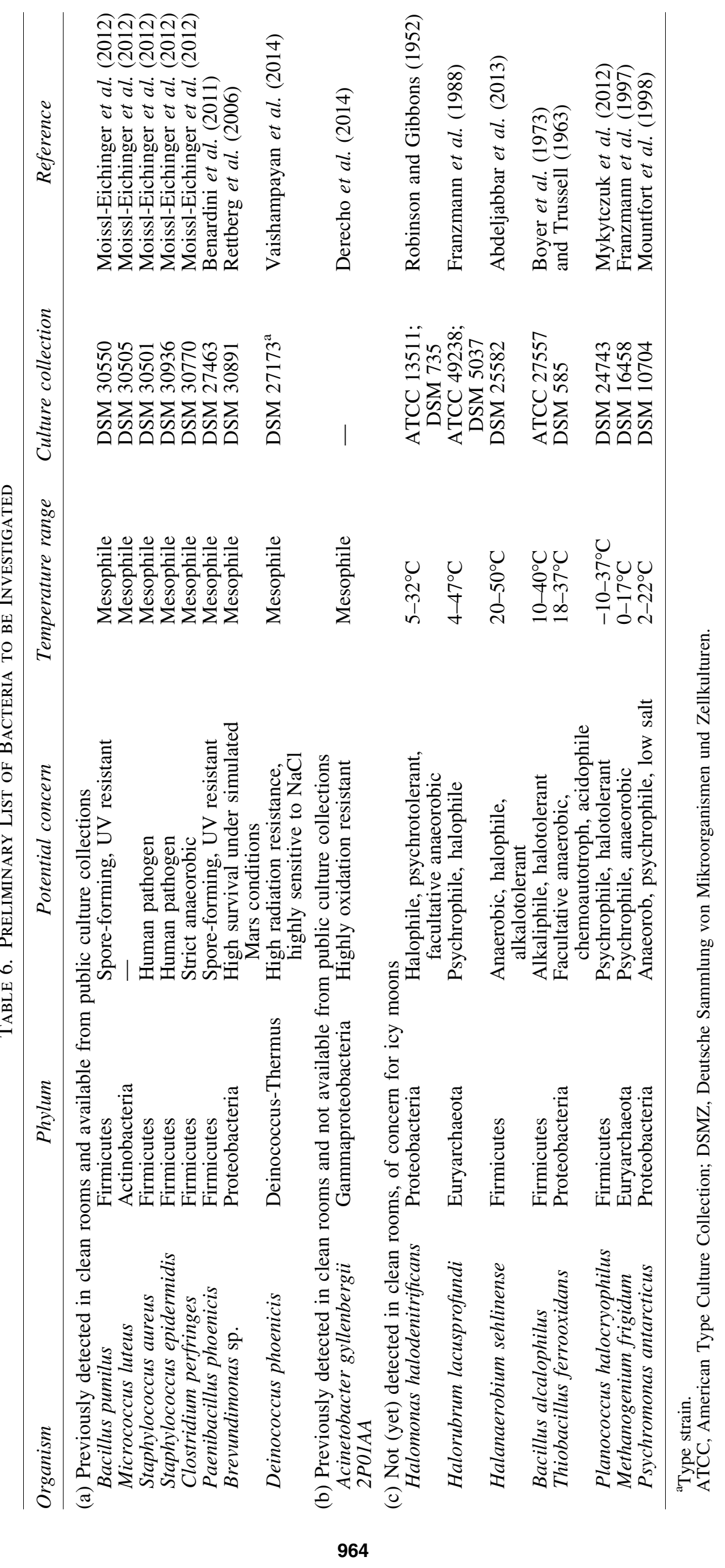


broad range of physiological capabilities, for example, (facultative) growth under anaerobic conditions, growth at low temperature, growth in the presence of salts (chlorides and sulfates), radiation resistance, desiccation resistance and association with humans, long-term use as model organism in space, or as a proxy for total bioburden in the actual standard assays for planetary protection.

The spacecraft assembly clean room isolates listed in Table 6A and B have been detected with the actual planetary protection standard assays that do not aim primarily at the identification and quantification of species relevant for icy moons. Some of these strains, namely any spore formers, might turn out to be problematic for icy moons. The list also includes taxa that have been shown to be active in icy moon analog environments (Table 6C), although they have not yet been isolated from clean rooms. Their inclusion is meant to further expand the physiological variability and better represent the total microbial diversity.

Based on the results to be expected from these investigations, a threshold for desiccation and radiation resistance of clean room microorganisms has to be defined, which allows the distinction of problematic species from nonproblematic species for icy moons.

Statement 7: The list of suggested test microorganisms should be seen as a draft, and open to later inclusions, updates, and revisions, depending on input from other experts and advances in our understanding of the microbiology of these locations as well as our knowledge on the environmental conditions on the icy moons of the outer Solar System.

\subsection{Proposed test organisms}

\subsubsection{Spacecraft assembly clean room isolates}

9.2.1.1. Bacillus pumilus. The Gram-positive aerobic rodshaped endospore-forming bacteria of the genus Bacillus are the most widely represented organisms in soil and are frequently recovered in clean rooms or space hardware assembly facilities. Spores survive the heat-shock step and are detected with the planetary protection standard assay. Members of this species are highly resistant to extreme environmental conditions such as low or no nutrient availability, desiccation, irradiation, $\mathrm{H}_{2} \mathrm{O}_{2}$, and chemical disinfections (Nicholson et al., 2000).

9.2.1.2. Paenibacillus phoenicis. This novel Grampositive motile endospore-forming aerobic bacterium was isolated from the NASA Phoenix lander assembly clean room that exhibits $100 \%$ 16S rRNA gene sequence similarity to two strains isolated from a deep subsurface environment (Bernadini et al., 2011). P. phoenicis spores survive the heat-shock step and are detected with the planetary protection standard assay. The endospores of this rod-shaped bacterium are resistant to UV radiation up to $500 \mathrm{~J} / \mathrm{m}^{2}$ (Bernardini et al., 2011). Growth occurs between $21^{\circ} \mathrm{C}$ and $50^{\circ} \mathrm{C}$, at $\mathrm{pH} 7.0-9.0$, and in the presence of $5 \% \mathrm{NaCl}$. Optimum growth occurs at $37^{\circ} \mathrm{C}$ and at $\mathrm{pH} 7.0$ (Bernadini et al., 2011).

9.2.1.3. Micrococcus luteus. Micrococcus luteus is a Gram-positive to Gram-variable nonmotile coccus saprotrophic bacterium that belongs to the family Micrococcaceae. $M$. luteus has been shown to survive in oligotrophic environments for extended periods of time, and has been frequently recovered from spacecraft assembly facilities (Rettberg et al., 2006). Members of this species survive the heat-shock step and are detected with the planetary protection standard assay.

9.2.1.4. Staphylococcus aureus. Staphylococcus aureus is a Gram-positive round-shaped facultative anaerobe that can grow in the absence of oxygen by fermentation or by using an alternative electron acceptor, and is frequently found in the human nose, respiratory tract, and skin (Masalha et al., 2001). Since the microbial testing of the Viking spacecraft in 1977 (Puleo et al., 1977), members of this species have been isolated and cultivated from samples obtained from clean room facilities. The genus Staphylococcus represents the most common nonspore-forming isolates recovered from clean room facilities (Smith et al., 2017) and, due to their pathogenic nature, pose a threat to human exploration.

9.2.1.5. Staphylococcus epidermidis. Similar to S. aure$u s$, this strain is associated with human skin. It colonizes predominantly the axillae, head, and nares and is the most frequently isolated species from human epithelia (Otto, 2009). Staphylococcus epidermidis is a Gram-positive cocci nonspore-forming organism that usually grows aerobically; however, reports suggest that strictly anaerobic strains of $S$. epidermidis exist (Rowlinson et al., 2006). Together with other species, the genus Staphylococcus represents the most common nonspore-forming isolates recovered from clean room facilities (Smith et al., 2017).

9.2.1.6. Clostridium perfringens. Clostridium perfringens is a Gram-positive rod-shaped anaerobic spore-forming pathogenic bacterium of the genus Clostridium. C. perfringens is omnipresent in nature and can be found as a normal component of decaying vegetation, marine sediment, the intestinal tract of humans, and other vertebrates, insects, and soil (Rood and Cole, 1991). Members of this species have been detected by molecular methods and cultivation assays in different spacecraft assembly facilities (Moissl et al., 2007; Stiegelmeier et al., 2009).

9.2.1.7. Brevundimonas ssp. The genus Brevundimonas comprises Gram-negative short rods that are 1 to $4 \mu \mathrm{m}$ long and $0.5 \mu \mathrm{m}$ in diameter. They grow aerobically between $30^{\circ} \mathrm{C}$ and $37^{\circ} \mathrm{C}$, no growth occurs at $4^{\circ} \mathrm{C}$, and no autotrophic growth occurs with $\mathrm{H}_{2}$ (Segers et al., 1994). Although this genus is nonspore forming, previous investigations uncovered that representative strains survive high doses of gamma radiation and frequent freeze-thaw cycles (Dartnell et al., 2010).

9.2.1.8. Acinetobacter gyllenbergii 2P01AA. Gramnegative gammaproteobacteria of the genus Acinetobacter are common soil organisms where they contribute to the degradation of aromatic compounds. In hospitals, other Acinetobacter species are a source of infections in debilitated patients. During the Mars Phoenix lander assembly, several hydrogen peroxide-resistant Acinetobacter strains have been isolated (Derecho et al., 2014). Among these, A. gyllenbergii 2P01AA exhibited the highest resistance.

9.2.2. Examples of species relevant for icy moons. 9.2.2.1. Halomonas halodenitrificans. Gram-negative coccus, $0.5 \mu \mathrm{m}$ in diameter, occurring singly or in pairs. Sodium chloride is necessary for growth and the organism dies at or $<2.2 \%$. The coccus grows optimally in medium containing between $4.4 \%$ and $8.8 \%$ sodium chloride; above $8.8 \%$, the 
length of the lag phase increases and the rate of growth decreases; however, growth is observed up to $24 \%$ (Robinson and Gibbons, 1952). The strains grow under aerobic or facultatively anaerobic conditions.

9.2.2.2. Halorubrum lacusprofundi. This strain was isolated from deep lake, Antarctica, and first described by Franzmann et al. in 1988. Unlike other halobacteria, the strains grow at $4^{\circ} \mathrm{C}$, although very slowly. Sodium chloride concentrations range from $1.5 \mathrm{~mol} / \mathrm{L}$ to saturation. The strain is not proteolytic, does not produce acids from sugars, but utilizes a wide range of carbon sources including sugars, alcohols, and organic acids for growth.

9.2.2.3. Halanaerobium sehlinense. This strictly anaerobic extremely halophilic Gram-positive rod-shaped bacterium was isolated from the hypersaline $(20 \% \mathrm{NaCl})$ surface sediments of Sehline Sebkha in Tunisia (Abdeljabbar et al., 2013). Halanaerobium sehlinense is nonspore forming, nonmotile, appearing singly or in pairs, or occasionally as long chains and measured $0.5-0.8 \mu \mathrm{m}$ by $3-10 \mu \mathrm{m}$. The organism is able to ferment glucose, galactose, fructose, glycerol, mannose, maltose, ribose, pyruvate, and sucrose. There are no previous reports about the resistance of this strain against desiccation and radiation.

9.2.2.4. Bacillus alcalophilus subsp. halodurans. Bacillus alcalophilus grows best in alkaline medium ( $\mathrm{pH}$ between 8 and 10) with mediocre growth at $\mathrm{pH} 7$. The strain is Grampositive, motile, rod, and spore forming as well as facultatively anaerobic (Boyer et al., 1973). Growth can be observed up to $15 \% \mathrm{NaCl}$, but higher concentrations need to be evaluated.

\subsubsection{Acidothiobacillus ferrooxidans. Acidothiobacillus} ferrooxidans is a chemolithotrophic autotroph able to obtain energy from the oxidation of ferrous iron or inorganic sulfur compounds (Tuovinen and Kelly, 1973). A. ferrooxidans is generally assumed to be an obligatory aerobic organism. However, under anaerobic conditions, ferric iron can replace oxygen as an electron acceptor for the oxidation of elemental sulfur (Bauermeister et al., 2014).

9.2.2.6. Planococcus halocryophilus. This aerobic Grampositive motile coccoid bacterial strain was isolated from permafrost active-layer soil collected from the Canadian High Arctic (Mykytczuk et al., 2012). Cells grow aerobically, are nonspore-forming, motile cocci, $0.8-1.2 \mu \mathrm{m}$ in diameter, and occur singly or in pairs. Planococcus halocryophilus is capable of growth over a broad temperature range, including subzero growth (below $-10^{\circ} \mathrm{C}$ to $37^{\circ} \mathrm{C}$ ), and at relatively high salinity $(0-19 \% \mathrm{NaCl})$.

9.2.2.7. Methanogenium frigidum. Methanogenium frigidum was isolated from the perennially cold anoxic hypolimnion of Ace Lake in the Vesfold Hills of Antarctica. The cells were psychrophilic, exhibiting most rapid growth at $15^{\circ} \mathrm{C}$, and no growth at temperatures $>18^{\circ} \mathrm{C}$ to $20^{\circ} \mathrm{C}$. The cells were irregular nonmotile coccoids (diameter 1.2$2.5 \mu \mathrm{m})$ that occurred singly and grew by $\mathrm{CO}_{2}$ reduction by using $\mathrm{H}_{2}$ as a reductant (Franzmann et al., 1997). Organisms are halotolerant and obligate psychrophile.

9.2.2.8. Psychromonas antarcticus. This Gram-negative rod- to oval-shaped aero-tolerant anaerobic bacterium was isolated from an anaerobic enrichment inoculated with sediment taken from below the cyanobacterial mat of a high-salinity pond near Bratina Island on the McMurdo Ice Shelf, Antarctica (Mountfort et al., 1998). Temperature range for growth, $2^{\circ} \mathrm{C}$ to $<22^{\circ} \mathrm{C}$, with optimum at $12^{\circ} \mathrm{C}$.

None of these problematic species has been investigated on their desiccation and radiation resistance in detail. It is, therefore, unclear at the moment whether they could survive a spaceflight to an icy moon and whether they could proliferate in the icy moons' subsurface oceans.

\subsection{Functional genomics}

(Gene-resolved) metagenomics (Zhang et al., 2010), single cell genomics, and other omics technologies have led to sophisticated systems biology approaches, which could give insights into microbial metabolism, microbial community functions, and their interactions with the environment (Hedlund et al., 2014; Cowan et al., 2015; Bashir et al., 2016; Minich et al., 2018). A functional genomics approach can be a suitable cultivation-independent method to identify problematic species and their metabolic function from clean room metagenome data. To understand the microbial physiology of microorganisms in a certain environment, it is necessary to consider not only the presence of specific genes but also their gene products, mRNA, proteins, and metabolites (Zhang et al., 2010; Manor et al., 2014).

The usefulness of the identification and quantification of indicator sequences/genes from metagenome data with respect to physiological capabilities pointing to problematic species should be tested by direct comparison with cultivation and stress test data obtained from comparable spacecraft assembly clean room samples. First steps to identify candidate genes/sequences responsible for the unusual resistance of some Bacillus species isolated from spacecraft assembly clean rooms to UV radiation and oxidative agents have already been performed (Tirumalai et al., 2013). Other examples are to investigate the DNA Damage Regulon with a radiation/desiccation response motif identified in highly radiation and desiccation-resistant bacteria (Anaganti et al., 2017) or genes and gene products necessary for other relevant metabolic processes like the potential for $\mathrm{H}_{2}$ oxidation or $\mathrm{H}_{2}$ production by hydrogenases (Brazelton et al., 2012).

However, this type of basic investigations takes time and requires research projects that are not coupled to specific space missions with tight schedules.

Recommendation 7: Screen clean room genomeresolved metagenomic data to identify microbial genes/ sequences that can be used as indicators for problematic species (desiccation resistance, radiation resistance, halophilic, anaerobic, and psychrophilic growth in low biomass microbial communities).

Recommendation 8: Verify whether the comparison of stress test results of clean room isolates and the identified microbial genes/sequences for specific physiological capabilities allows the assessment of the physiological potential of the clean room microbiota qualitatively and quantitatively. 
FIG. 4. Suggested new standard assay for problematic species.

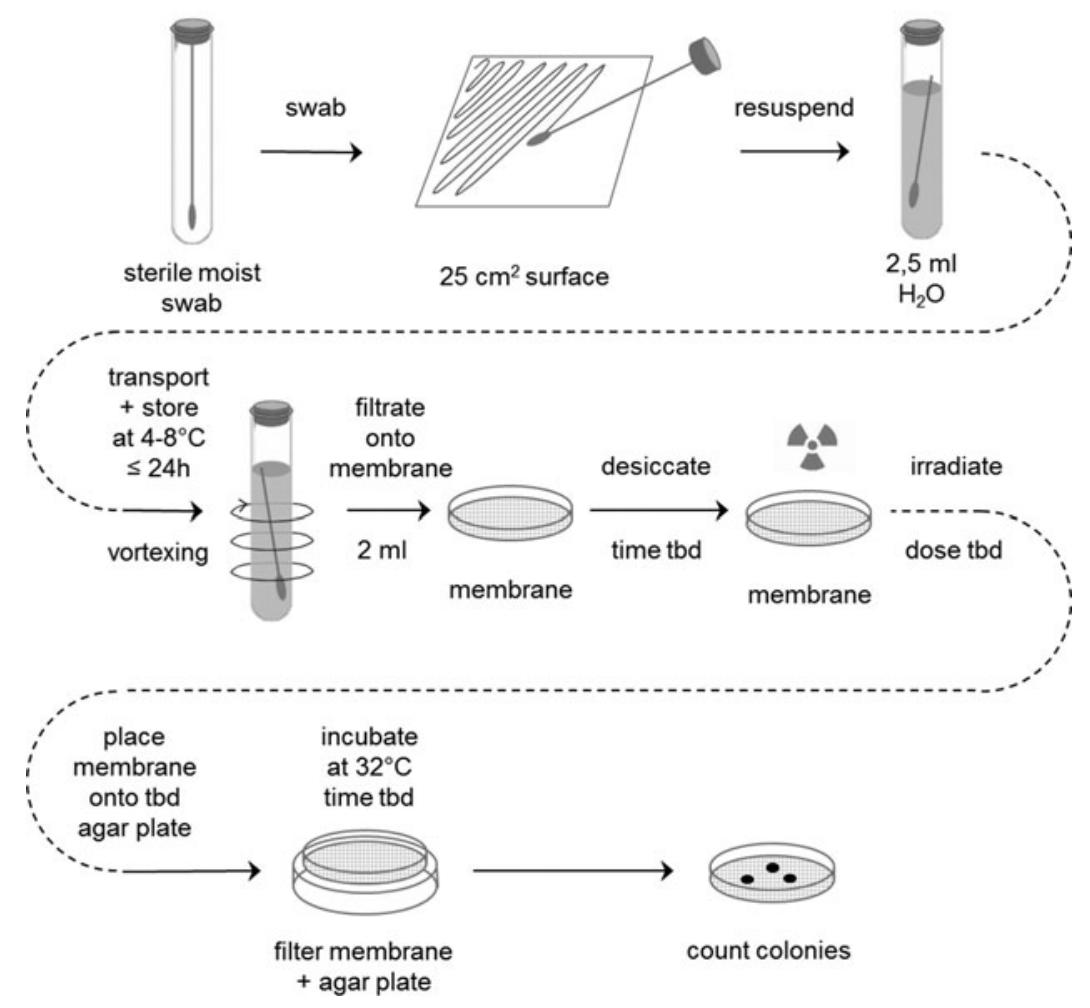

\section{Short-term Research Activities for the Development of New Planetary Protection Assays for the Next Icy Moons Missions}

As already mentioned due to time constraints, cultivation assays for all potentially problematic species are not suitable for routine clean room monitoring and planetary protection bioburden measurements during assembly, integration, and testing activities.

For near future missions to the outer Solar System, there is a need for new fast assays whose results are indicative for problematic species and take into account the most challenging environmental factors (i.e., desiccating conditions and exposure to high doses of radiation). Investigations were already initiated in 2001 by Chen et al. In their study, clean room samples were exposed to a radiation dose of $10 \mathrm{kGy}$. No surviving microorganisms could be found, but $16 \mathrm{~S}$ rDNA fragments could still be amplified. A systematic investigation is necessary as a basis for the definition of a new bioburden assay and corresponding new bioburden limits for problematic species.

Recommendation 9: Define and evaluate a new planetary protection bioburden assay for icy moons based on preselection steps in terms of desiccation and radiation exposure.

Recommendation 10: Define bioburden limits for missions to icy moons based on the knowledge about the problematic species in clean rooms, their physiological capabilities, and the to be defined new bioburden assay.

One first practical approach for the final assay could be the concentration of microorganisms from clean room and spacecraft samples on membrane filters, followed by a desiccation step under controlled conditions and an irradiation step with ionizing radiation (duration of desiccation and dose of radiation to be defined). As already described, space radiation, consisting of sparsely and densely ionizing radiation, is very complex and cannot be reproduced on Earth. Therefore, the use of X-rays as a proxy for space radiation is recommended, even if the induced cell damages are not totally identical to those resulting from the absorbance of HZE particles or the exposure to space radiation. An example of a possible assay for swab samples is shown in Fig. 4.

\section{Summary}

To define new planetary protection bioburden assays relevant for icy moons, systematic investigations should aim to (i) identify potential problematic species for icy moons in clean rooms by applying a combination of cultivationdependent and cultivation-independent methods, (ii) develop/optimize methods for the discrimination between dead and alive microorganisms, (iii) determine the resistance of representative clean room contaminants to simulated mission parameters (e.g., vacuum and ionizing radiation), (iv) determine the resistance of the potential problematic species to the environmental conditions of the mission target (e.g., radiation, salts, and low temperature), and (v) develop suitable new planetary protection assays for icy moons and derive threshold values (e.g., irradiation doses and desiccation duration) from (iii) and (iv) for problematic species that can serve as proxies for all potential problematic species from clean rooms.

\section{Author Disclosure Statement}

No competing financial interests exist. 


\section{References}

Abdeljabbar, H., Cayol, J.L., Hania, W.B., Boudabous, A., Sadif, N., and Fardeau, M.L. (2013) Halanaerobium sehlinense sp. nov., an extremely halophilic, fermentative, strictly anaerobic bacterium from sediments of the hypersaline lake Sehline Sebkha. Int J Syst Evol Microbiol 63:2069-2074.

Anaganti, N., Basu, B., Mukhopadhyaya, R., and Apte, S.K. (2017) Proximity of radiation desiccation response motif to the core promoter is essential for basal repression as well as gamma radiation-induced gyrB gene expression in Deinococcus radiodurans. Gene 615:8-17.

Anderson, J.D., Schubert, G., Jacobson, R.A., Lau, E.L., Moore, W.B., and Sjogren, W.L. (1998) Europa's differentiated internal structure: inferences from four Galileo encounters. Science 281:2019-2022.

Antunes, A., Ngugi, D.K., and Stingl, U. (2011) Microbiology of the Red Sea (and other) deep-sea anoxic brine lakes. Environ Microbiol Rep 3:416-433.

Antunes, A., Alam, I., Simoes, M.F., Daniels, C., Ferreira, A.J.S., Siam, R., El-Dorry, H., and Bajic, V.B. (2015) First insights into the viral communities of the deep-sea anoxic brines of the Red Sea. Genomics Proteomics Bioinf 13:304-309.

Baltschukat, K. and Horneck, G. (1991) Responses to accelerated heavy ions of spores of Bacillus subtilis of different repair capacity. Radiat Environ Biophys 30:87-103.

Barth, V.C., Cattani, F., Ferreira, C.A.S., and Oliveira, S.D. (2012) Sodium chloride affects propidium monoazide action to distinguish viable cells. Anal Biochem 428:108-110.

Bashir, M., Ahmed, M., Weinmaier, T. Ciobanu, D., Ivanova, N., Pieber, T.R., and Vaishampayan, P.A. (2016) Functional metagenomics of spacecraft assembly cleanrooms: presence of virulence factors associated with human pathogens. Front Microbiol 7:1321.

Bauermeister, A., Moeller, R., Reitz, G., Sommer, S., and Rettberg, P. (2011) Effect of relative humidity on Deinococcus radiodurans' resistance to prolonged desiccation, heat, ionizing, germicidal, and environmentally relevant UV radiation. Microbial Ecol 61:715-722.

Bauermeister, A., Rettberg, P., and Flemming, H.-C. (2014) Growth of the acidophilic iron-sulfur bacterium Acidithiobacillus ferrooxidans under Mars-like geochemical conditions. Planet Space Sci 98:205-215.

Beblo, K., Douki, T. Schmalz, G., Rachel, R., Wirth, R., Huber, H., Reitz, G., and Rettberg, P. (2011) Survival of thermophilic and hyperthermophilic microorganisms after exposure to UV-C, ionizing radiation and desiccation. Arch Microbiol 193:797-809.

Behrendt, U., Schumann, P., Stieglmeier, M., Pukall, R., Augustin, J., Spröer, C., Schwendner, P., Moissl-Eichinger, C., and Ulrich, A. (2010) Characterization of heterotrophic nitrifying bacteria with respiratory ammonification and denitirification activity-description of Paenibacillus uligunis sp. nov., an inhabitant of fen peat soil and Paenibacillus purispattii sp. nov., isolated from a spacecraft assembly clean room. Syst Appl Microbiol 33:328-336.

Benardini, J.N., Vaishampayan, P.A., Schwendner, P., Swanner, E., Fukui, Y., Osman, S., Satomi, M., and Venkateswaran, K. (2011) Paenibacillus phoenicis sp. nov., isolated from the Phoenix lander assembly facility and subsurface molybdenum mine. Int J Syst Evol Microbiol 61:1338-1343.

Billi, D., Viaggiu, E., Cockell, C.S., Rabbow, E., Horneck, G., and Onofri, S. (2011) Damage escape and repair in dried Chroococcidiopsis spp. from hot and cold deserts exposed to simulated space and martian conditions. Astrobiology 11:65-73.
Boyer, E.W., Ingle, M.B., and Mercer, G.D. (1973) Bacillus alcalophilus subsp. halodurans subsp. nov.: an alkalineamylase-producing, alkalophilic organism. Int J Syst Bacteriol 23:238-242.

Brazelton, W.J., Nelson, B., and Schrenk, M.O. (2012) Metagenomic evidence for $\mathrm{H}_{2}$ oxidation and $\mathrm{H}_{2}$ production by serpentinite-hosted subsurface microbial communities. Front Microbiol 2:268.

Bryce, C.C., Horneck, G., Rabbow, E., Edwards, H.G.M., and Cockell, C.S. (2015) Impact shocked rocks as protective habitats on an anoxic early Earth. Int J Astrobiol 14:115-122.

Burns, D.G., Janssen, P.H., Itoh, T., Kamekura, M., Li, Z., Jensen, G., Rodríguez-Valera, F., Bolhuis, H., and DyallSmith, M.L. (2007) Haloquadratum walsbyi gen. nov., sp. nov., the square haloarchaeon of Walsby, isolated from saltern crystallizers in Australia and Spain. Int J Syst Evol Microbiol 57:387-392.

Callegan, R.P., Nobre, M.F., McTernan, P.M., Battista, J.R., Navarro-Gonzalez, R., McKay, C.P., da Costa, M.S., and Rainey, F.A. (2008) Description of four novel psychrophilic, ionizing radiation-sensitive Deinococcus species from alpine environments. Int J Syst Evol Microbiol 58:1252-1258.

Cassidy, T., Coll, P., Raulin, F., Carlson, R.W., Johnson, R.E., Loeffle, M.J., Hand, K.P., and Baragiola, R.A. (2010) Radiolysis and photolysis of icy satellite surfaces: experiments and theory. Space Sci Rev 153:299-315.

Chapelle, E.W. and Levin, G.V. (1968) Use of the firefly bioluminescence reaction of rapid detection and counting of bacteria. Biochem Med 2:41-52.

Chen, F., La Duc, M.T., Baker, A., Koukol, R., Barengoltz, J., Kern, R., and Venkateswaran, K. (2001) Developing Planetary Protection Technology: Microbial Diversity and Radiation Resistance of Microorganisms in a Spacecraft Assembly Facility. American Geophysical Union 2001 Fall Meeting December 10-14, San Francisco. Available online at https:// trs.jpl.nasa.gov/bitstream/handle/2014/13201/01-1889.pdf? sequence $=1$

Cockell, C.S., Bush, T., Bryce, C., Direito, S., Fox-Powell, M., Harrison, J.P., Lammer, H., Landenmark, H., Martin-Torres, J, Nicholson, N., Noack, L., O’Malley-James, J., Payler, S.J., Rushby, A., Samuels, Z., Schwendner, P., Wadsworth, J., and Zorzano, M.P. (2016) Habitabiliy: a review. Astrobiology 16: 89-117.

Cooper, J.F., Johnson, R.E., Mauk, B.H., Garrett, H.B., and Gehrels, N. (2001) Energetic ion and electron irradiation of the icy galilean satellites. Icarus 149:133-159.

Cowan, D.A., Ramond, J.-B., Makhalanyane, T.P., and De Maayer P. (2015) Metagenomics of extreme environments. Curr Opin Microbiol 25:97-102.

Cucinotta, F.A., To, K., and Cacao, E. (2017) Predictions of space radiation fatality risk for exploration missions. Life Sci Space Res 13:1-11.

Daly, M.J. and Minton, K.W. (1996) An alternative pathway of recombination of chromosomal fragments precedes recAdependent recombination in the radioresistant bacterium Deinococcus radiodurans. J Bacteriol 178:4461-4471.

Dartnell, L.R., Hunter, S.J., Lovell, K.V., Coates, A.J, and Ward, J.M. (2010) Low-temperature ionizing radiation resistance of Deinococcus radiodurans and Antarctic Dry Valley bacteria. Astrobiology 10:717-732.

Derecho, I., Mc Coy, K.B., Vaishampayan, P., Venkateswaran, K., and Mogul, R. (2014) Characterization of hydrogen peroxide-resistant Acinetobacter species isolated during the Mars phoenix spacecraft assembly. Astrobiology 14:837-847. 
Dieser, M., Nocker, A., Priscu, J.C., and Foreman, C.M. (2010) Viable microbes in ice: application of molecular assays to McMurdo Dry Valley lake ice communities. Antarct Sci 22:470-476.

ECSS-Q-ST-70-55C. (2008) Microbial Examination of Flight Hardware and Cleanrooms. ESA Requirements and Standards Division, ESTEC, Noordwijk, The Netherlands.

ECSS-Q-ST-70-57C. (2013) Dry Heat Bioburden Reduction for Flight Hardware. ESA Requirements and Standards Division, ESTEC, Noordwijk, The Netherlands.

Faglaiarone, C., Mosca, C., Ubaldi, I., Verseux, C., Baque, M., Wilmotte, A., and Billi, D. (2017) Avoidance of protein oxidation correlates with the desiccation and radiation resistance of hot and cold desert strains of the cyanobacterium Chroococcidiopsis. Extremophiles 21:981-991.

Fittipaldi, M., Codony, F., Adrados, B., Camper, A.C., and Morato, J. (2011) Viable real-time PCR in environmental samples: can all data be interpreted directly? Microb Ecol 61:7-12.

Foster, T.L. and Winans, L. (1975) Psychrophilic microorganisms from areas associated with the Viking spacecraft. Appl Microbiol 30:546-550.

Franzmann, P.D., Stackebrandt, E., Sanderson, K., Volkman, J.K., Cameron, D.E., Stevenson, P.L., McMeekin, T.A., and Burton, H.R. (1988) Halobacterium lacusprofundi sp. nov., a halophilic bacterium isolated from Deep Lake, Antarctica. Syst Appl Microbiol 11:20-27.

Franzmann, P.D., Liu, Y., Balkwill, D.L., Aldrich, H.C., Conway de Macario, E., and Boone, D.R. (1997) Methanogenium frigidum sp.nov., a psychrophilic, H2-using methanogen from Ace Lake, Antarctica. Int J Syst Bacteriol 47:1068-1072.

Fredrickson, J.K., Li, S.W., Gaidamakova, E.K., Matrosova, V.Y., Zhai, M., Sulloway, H.M., Scholten, J.C., Brown, M.G., Balskwill, D.L., and Daly, M.J. (2008) Protein oxidation: key to bacterial desiccation resistance? ISME J 2:393-403.

Gabani, P. and Singh, O.V. (2013) Radiation-resistant extremophiles and their potential in biotechnology and therapeutics. Appl Microbiol Biotechnol 97:993-1004.

Garrett, H.G., Ratliff, J.M., and Evans, R.W. (2005) Saturn radiation (SATRAD) model. JPL Publ 05-9:1-116.

Ghosh, S., Osman, S., Vaishampayan, P., and Venkateswaran, K. (2010) Recurrent isolation of extremotolerant bacteria from the clean room where Phoenix spacecraft components were assembled. Astrobiology 10:325-335.

Gieseler, J., Heber, B., Dunzlaff, P., Müller-Mellin, R., Klassen, A., Gomez-Herrero, R., Kunow, H., Wimmer-Schweingruber, R., and Mewaldt, R.A. (2008) The radial gradient of galactic cosmic rays: ulysses KET and ACE CRIS measurements. ICRC 2007 Proceedings of the 30th International Cosmic Ray Conference, July 3-11, 2007, Mérida, Yucatán, Mexico.

Goodman, J.C., Collins, G.C., Marshall, J., and Pierrehumbert, R.T. (2004) Hydrothermal plume dynamics on Europa: Implications for chaos formation. Journal of Geophysical Research: Planets, 109 (E3).

Grant, W.D. (2004) Life at low water activity. Philos Trans $R$ Soc London Ser B Biol Sci 359:1249-1266.

Greeley R., Chyba, C.F., Head, J.W.I., McCord, T.B., McKinnon, W.B., Pappalardo, R.T., and Figueredo P.H. (2004) Geology of Europa. In Jupiter: The Planet, Satellites and Magnetosphere, edited by W.B. McKinnon, Cambridge University Press, Cambridge, Chapter 15, 2004.

Green, J. and Paget, M.S. (2004) Bacterial redox sensors. Nat Rev 2:954-967.

Greenberg, R. (2010) Transport rates of radiolytic substances into Europa's ocean: implications for the potential origin and maintenance of life. Astrobiology 10:275-283.
Guo, F. and Zhang, T. (2014) Detecting the nonviable and heattolerant bacteria in activated sludge by minimizing DNA from dead cells. Environ Microbiol 67:829-836.

Harrison, J.P., Gheeraer, N., Tsigelnitskiy, D., and Cockell, C.S. (2013) The limits for life under multiple extremes. Trends Microbiol 21:204-212.

Hassler, D.M., Zeitlin, C., Wimmer-Schweingruber, R.F., and Böttcher, S. (2012) The Radiation Assessment Detector (RAD) investigation. Space Sci Rev 170:503-558.

He, C. and Smith, M.A. (2014) Identification of nitrogenous organic species in Titan aerosols analogs: implication for prebiotic chemistry on Titan and early Earth. Icarus 238:8692.

Hedlund, B.P., Dodsworth, J.A., Murugapiran, S.K., Rinke, C., and Woyke, T. (2014) Impact of single-cell genomics and metagenomics on the emerging view of extremophile "microbial dark matter'. Extremophiles 18:865-875.

Henrickson, R., Lundgren, P., Mohan, G.B.M., Urbaniak, C., Bernardini, J.N., and Venakateswaran, K. (2017) Comprehensive measurement of microbial burden in nutrientdeprived cleanrooms. ICES 2017:177.

Horneck, G., Bucker, H., and Reitz, G. (1994a) Long-term survival of bacterial spores in space. Adv Space Res 14:4145.

Horneck, G., Krasavin, E.A., and Kozubek, S. (1994b) Mutagenic effects of heavy ions in bacteria. Adv Space Res 14: 315-329.

Horneck, G., Eschweiler, U., Reitz, G., Wehner, J., Willimek, R., and Strauch, K. (1995) Biological responses to space: results of the experiment "exobiological unit" of ERA on EURECA I. Adv Space Res 16:105-118.

Horneck, G., Rettberg, P., Rabbow, E., Strauch, W., Seckmeyer, G., Facius, R., Reitz, G., Strauch, K., and Schott, J.U. (1996) Biological dosimetry of solar radiation for different simulated ozone column thicknesses. J Photochem Photobiol B 32:189_ 196.

Hsu, H.-W., Postberg, F., Sekine, Y., Shibuya, T., Kempf, S., Horanyi, M., Juhasz, A., Altobelli, N., Suzuki, K., Masaki, Y., Kuwatani, T., Tachibana, S., Sirono, S.I., MoragasKlostermeyer, G., and Srama, R. (2015) Ongoing hydrothermal activities within Enceladus. Nature 519:207-210.

Hugerth, L.W. and Andersson, A.F. (2017) Analysing microbial community composition through amplicon sequencing: from sampling to hypothesis testing. Front Microbiol 8:1561.

Iess, L., Stevensom, D.J., Parisi, M., Hemingway, D., Jocobson, R.A., Lunine, J.I., Nimmo, F. Armstrong, J.W., Asmar, S.W., Duci, M., and Tortora, P. (2014) The gravity field and interior structure of Enceladus. Science 344:78-80.

Jun, I., Garrett, H.B., Swimm, R., Evans, R.W., and Clough, G. (2005) Statistics of the variations of the high-energy electron population between 7 and 28 jovian radii as measured by the Galileo spacecraft. Icarus 178:386-394.

Kargel, J.S., Kaye, J.Z., Head, J.W., Marion, G.M., Sassen, R., Crowley, J.K., Ballesteros, O.P., Grant, S.A., and Hogenboom, D.L. (2000) Europa's crust and ocean: origin, composition, and the prospects for life. Icarus 148:226-265.

Kempf, M.J., Chen, F., Kern, R., and Venkateswaran, K. (2005) Recurrent isolation of hydrogen peroxide-resistant spores of Bacillus pumilus from a spacecraft assembly facility. Astrobiology 5:391-405.

Khurana, K.K., Kivelson, M.G., Stevenson, D.J., Schubert, G., Russell, C.T., Walker R.J., and Polanskey, C. (1998) Induced-magnetic fields as evidence for subsurface oceans in Europa and Callisto. Nature 395:777-780. 
Khurana, K.K., Kivelson, M.G., Hand, K.P., and Russel, C.T. (2008) Electromagnetic induction from Europa's ocean and the deep interior. In Europa, edited by R.T. Pappalardo, W.B. McKinnon, and K. Khurana. University of Arizona Press, Tucson, pp 571-586.

Kimura, J. and Kitadai, N. (2015) Polymerization of building blocks of life on Europa and other icy moons. Astrobiology 15:430-441.

Kivelson, M.G., Khurana, K.K., Russell, C.T., Volwerk, M., Walker, R.J., and Zimmer, C. (2000) Galileo magnetometer measurements: a stronger case for a subsurface ocean at Europa. Science 289:1340-1343.

Kivelson, M.G., Khurana, K.K., and Volwerk, M. (2002) The permanent and inductive magnetic moments of Ganymede. Icarus 157:507-522.

Kminek, G., Conley, C., Hipkin, V., and Yano, H. (2017) COSPAR's planetary protection policy. Space Res Today 200:12-25.

La Duc, M.T., Nicholson, W., Kern, R., and Venkateswaran, K. (2003) Microbial characterization of the Mars Odyssey spacecraft and its encapsulating facility. Environ Microbiol 5: 977-985.

La Duc, M.T., Kern, R., and Venkateswaran, K. (2004a) Microbial monitoring of spacecraft and associated environments. Microb Ecol 47:150-158.

La Duc, M.T., Satomi, M., and Venkateswaran, K. (2004b) Bacillus odysseyi sp. nov., a round-spore-forming bacillus isolated from the Mars Odyssey spacecraft. Int J Syst Evol Microbiol 54:195-201.

La Duc, M.T., Osman, S., Vaishampayan, P., Piceno, Y., Andersen, G., Spry, J.A., and Venkateswaran, K. (2009) Comprehensive census of bacteria in clean rooms by using DNA microarray and cloning methods. Appl Environ Microbiol 75: 6559-6567.

La Duc, M.T., Vaishampayan, P., Nilsson, H.R., Torok, T., and Venkateswaran, K. (2012) Pyrosequencing-derived bacterial, archaeal, and fungal diversity of spacecraft hardware destined for Mars. Appl Environ Microbiol 78:5912-5922.

Link, L., Sawyer, J., Venkateswaran, K., and Nicholson, W. (2004) Extreme spore UV resistance of Bacillus pumilus isolates obtained from an ultraclean spacecraft assembly facility. Microb Ecol 47:159-163.

Madigan, M.T., Martinko, J.M., Dunlap, P.V. and Clark, D.P. 2009. Brock Biology of Microorganisms, $12^{\text {th }}$ ed. Pearson Benjamin-Cummings, San Francisco.

Mahaffy, P.R., Beaty, D.W., Anderson, M.S., Aveni, G., Bada, J.L., Clemett, S.J., Des Marais, D.J., Douglas, S., Dworkin, J.P., Kern, R.G., Papanastassiou, D.A., Palluconi, F.D., Simmonds, J.J., Steele, A., Waite, J.H., and Zent, A.P. (2004) Science priorities related to the organic contamination of martian landers. Unpublished white paper, $32 \mathrm{pp}$, posted November 2004. https:// mepag.jpl.nasa.gov/reports/OCSSG_final_report_Nov_2004.pdf

Marquis, R.E. and Bender, G.R. (1985) Mineralization and heat resistance of bacterial spores. J Bacteriol 161:789-791.

Masalha, M., Borovok, I., Schreiber, R., Aharonowitz, Y., and Cohen, G. (2001) Analysis of transcription of the Staphylococcus aureus aerobic class $1 \mathrm{~b}$ and anaeorobic class III ribonucleotide reductase genes in response to oxygen. $J$ Bacteriol 183:7260-7272.

McCord, T.B., Hansen, G.B., Combe, J.-P., and Hayne, P. (2010) Hydrated minerals on Europa's surface: an improved look from the Galileo NIMS investigation. Icarus 209:639-650.

McKay, C.P., Anbar, A.D., Porco, C., and Tsou, P. (2014) Follow the plume: the habitability of Enceladus. Astrobiology 14:352-355.
Melosh, H.J., Ekholm, A.G., Showman, A.P., and Lorenz, R.D. (2004) The temperature of Europa's subsurface water ocean. Icarus 168:498-502.

Meltzer, M. (2011) When Biospheres Collide: A History of NASA's Planetary Protection Programs. NASA-SP-20114234. ISBN-978-0-16-085327-2. US Government Printing Office (http://bookstore.gpo.gov), P.O. Box 979050, St. Louis, Missouri, USA.

Minich, J.J., Zhu, Q., Janssen, S., Hendrickson, R., Amir, A., Vetter, R., Hyde, J., Doty, M.M., Stillwell, K., Benardini, J., Kim, J.H., Allen, E.E., Venkateswaran, K., and Knight, R. (2018) KatharoSeq enables high-throughput microbiome analysis from low-biomass samples. Novel Systems Biol Tech 3:e00218-17.

Moeller, R., Ragu, M., Leuko, S., Berger, T., Hellweg, C.E., Fujimori, A. Okayasu, R., Horneck, G., and the STARLIFE Research Group. (2017) STARLIFE-an International Campaign to Study the role of galactic cosmic radiation in astrobiological model systems. Astrobiology 17:101-109.

Mohapatra, B.R., and La Duc, M.T. (2012) Rapid detection of viable Bacillus pumilus SAFR-032 encapsulated spores using novel propidium monoazide-linked fluorescence in situ hybridization. J Microbiol Methods 90:15-19.

Moissl, C., Osman, S., La Duc, M.T., Dekas, A., Brodie, E., DeSantis, T., and Venkateswaran, K. (2007b) Molecular bacterial community analysis of clean rooms where spacecraft are assembled. FEMS Microbial Ecol 61:509-521.

Moissl, C., Bruckner, J.C., and Venkateswaran, K. (2008) Archaeal diversity analysis of spacecraft assembly clean rooms. ISME J 2:115-119.

Moissl-Eichinger, C. (2011) Archaea in artificial environments: their presence in global spacecraft clean rooms and impact on planetary protection. ISME J 5:209-219.

Moissl-Eichinger, C., Rettberg, P., and Pukall, R. (2012) The first collection of spacecraft-associated microorganisms: a public source of extremotolerant microorganisms from spacecraft assembly clean rooms. Astrobiology 12:1024-1034.

Moissl-Eichinger, C., Auerbach, A.K., Probst, A.J., Mahnert, A., Tom, L., Piceno, Y., Andersen, G.L., Venkateswaran, K., Rettberg, P., Barczyk, S., Pukall, R., and Berg, G. (2015) Quo vadis? Microbial profiling revealed strong effects of cleanroom maintenance and routes of contamination in indoor environments. Sci Rep 5:9156.

Moissl-Eichinger, C., Cockell, C., and Rettberg, P. (2016) Venturing into new realms? Microorganisms in space. FEMS Microbiol Rev 40:722-737.

Monor, O., Levy, R., and Borenstein, A. (2014) Mapping the inner workings of the microbiome: genomic- and metagenomic-based study of metabolism and metabolic interactions in the human microbiome. Cell Metab 20:742-752.

Moseley, B.E.B. (1983) Photobiology and radiobiology of $\mathrm{Mi}$ crococcus (Deinococcus) radiodurans. Photochem Photobiol Rev 7:223-274.

Mountfort, D.O., Rainey, F.A., Burghardt, J., Kaspar, H.F., and Stackebrandt, E. (1998) Psychromonas antarcticus gen. nov., sp. nov., a new aerotolerant anaerobic, halophilic psychrophile isolated from pond sediment of the McMurdo Ice Shelf, Antarctica. Arch Microbiol 169:231-238.

Mykytczuk, N.C.S., Wilhelm, R.C., and Whyte, L.G. (2012) Planococcus halocryophilus sp. nov., and extreme sub-zero species from high Arctic permafrost. Int J Syst Evol Microbiol 62:1937-1944.

NASA-HDBK-6022. (2010) Handbook for the Microbial Examination of Space Hardware, National Aeronautics and Space Administration, Washington, DC, 20546-0001 
Neish, C.D., Somogyi, Á., and Smith, M.A. (2010) Titan's primordial soup: formation of amino acids via lowtemperature hydrolysis of tholins. Astrobiology 10:337-347.

Newcombe, D.A., La Duc, M.T., Vaishampayan, P., and Venkateswaran, K. (2008) Impact of assembly, testing and launch operations on the airborne bacterial diversity within a spacecraft assembly facility clean-room. Int J Astrobiol 7:223-236.

Newcombe, D., Dekas, A., Mayilraj, S., and Venkateswaran, K. (2009) Bacillus canaveralius sp. nov., an alkali-tolerant bacterium isolated from a spacecraft assembly facility. Int $J$ Syst Evol Microbiol 59:2015-2019.

Nicholson, W.L., Munakata, N., Horneck, G., Melosh, H.J., and Setlow, P. (2000) Resistance of Bacillus endospores to extreme terrestrial and extraterrestrial environments. Microbiol Mol Biol Rev 64:548-572.

Nocker, A., Cheung, C.Y., and Camper, A.K. (2006) Comparison of propidium monoazide with ethidium monoazide for differentiation of live vs. dead bacteria by selective removal of DNA from dead cells. J Microbiol Methods 67:310-320.

Oremland, R.S., Saltikov, C.W., Stolz, J.F., and Hollibaugh, J.T. (2017) Autotrophic microbial arsenotrophy in arsenicrich soda lakes. FEMS Microbiol Lett 364:fnx146.

Osman, S., Satomi, M., and Venkateswaran, K. (2006) Paenibacillus pasadenensis sp. nov., and Paenibacillus barengoltzii sp. nov., isolated from a spacecraft assembly facility. Int J Syst Evol Microbiol 56:1509-1514.

Otto, M. (2009) Staphylococcus epidermidis-the "accidental" pathogen. Nat Rev Microbiol 7:555-567.

Pappalardo, R.T., Belton, M.J.S., Breneman, H.H., Carr, M.H., Chapman, C.R., Collins, G.C., Denk, T., Fagents, S., Geissler, P.E., Giese, B., Greeley, R., Greenberg, R., Head, J.W., Helfenstein, P., Hoppa, G., Kadel, S.D., Klaaen, K.P., Klemaszewski, J.E., Magee, K., McEwen, A.S, Moore, J.M., Moore, W.B., Neukum, G., Phillips, C.B., Prockter, L.M., Schubert, G., Senske, D.A., Sullivan, R.J., Tufts, B.R., Turtle, E.P., Wagner, R., and Williams, K.K. (1999) Does Europa have a subsurface ocean? Evaluation of the geological evidence. J Geophys Res 104:24015-24055.

Paranicas, C., Mauk, B.H., Khurana, K., Jun, I., Garrett, H., Krupp, N., and Roussos, E. (2007) Europa's near-surface radiation environment. Geophys Res Lett 34:529-544.

Paranicas, C., Mitchell, D.G., Krimigis, S.M., Hamilton, D.C., Roussos, E., Krupp, N., ... and Armstrong, T.P. (2008) Sources and losses of energetic protons in Saturn's magnetosphere. Icarus 197:519-525.

Paranicas, C., Cooper, J., Garrett, H.B., Johnson, R.E., Sturner, S.J. (2009) Europa's radiation environment and its effects on the surface. In Europa, edited by W.M. Rt Pappalardo, K. Khurana., University of Arizona Press, Tucson, AZ, pp. 529-544.

Pascal, R. (2016) Physicochemical requirements inferred for chemical self-organization hardly support an emergence of life in the deep oceans of icy moons. Astrobiology 16:328-334.

Pavlopoulou, A., Savva, G.D., Louka, M., Bagos, P.G., Vorgias, C.E., Michalopoulos, I., and Georgakilas, A.G. (2016) Unraveling the mechanisms of extreme radioresistance in prokaryotes: lessons from nature. Mutat Res Rev Mutat Res767:92-107.

Pavlov, A.A., Vasilyev, G., Ostryakov, V.M., Pavlov, A.K., and Mahaffy, P. (2012) Degradation of the organic molecules in the shallow subsurface of Mars due to irradiation by cosmic rays. Geophys Res Lett 39:L13202.

Pedrós-Alió, C., Calderón-Paz, J.I., Maclean, M.H., Medina, G., Marrasé, C., Gasol, J.M., and Guixa-Boixereu, N. (2000) The microbial food web along salinity gradients. FEMS Microbiol Ecol 32:143-155.
Probst, A., Vaishampayan, P., Osman, S., Moissl-Eichinger, C., Andersen, G.L., and Venkateswaran, K. (2010) Diversity of anaerobic microbes in spacecraft assembly clean rooms. Appl Environ Microbiol 76:2837-2845.

Puleo, J.R., Fields, N.D., Moore, B, and Graves, R.C. (1970a) Microbial contamination associated with the Apollo 6 spacecraft during final assembly and testing. Space Life Sci 2:48-56.

Puleo, J.R., Oxborrow, G.S., Fields, N.D., and Hall, H.E. (1970b) Quantitative and qualitative microbiological profiles of the Apollo 10 and 11 spacecraft. Appl Microbiol 20:384-389.

Puleo, J.R., Oxborrow, G.S., Fields, N.D., Herring, C.M., and Smith, L.S. (1973) Microbiological profiles of four Apollo spacecraft. Appl Microbiol 26:838-845.

Puleo, J.R., Fields, N.D., Bergstrom, S.L., Oxborrow, G.S., Stabekis, P.D., and Koukol, R.C. (1977) Microbiological profiles of the Viking spacecraft. Appl Environ Microbiol 33: 379-384.

Pulschen, A.A., Bendia, A.G., Fricker, A.D., Pellizari, V.H., Galante, G., and Rodrigues, F. (2017) Isolation of uncultured bacteria from antarctica using long incubation periods and low nutritional media. Front Microbiol 8:1346.

Rabbow, E., Rettberg, P., Parpart, A., Panitz, C. Schult, W., Molter, F., Jaramillo, E., Demets, R., Weiß, P., and Willnecker, R. (2017) EXPOSE-R2: the astrobiological ESA mission on board of the international space station. Front Microbiol 8:1533.

Rawsthorne, H., Dock, C.N., and Jaykus, L.A. (2009) PCRbased method using propidium monoazide to distinguish viable from nonviable Bacillus subtilis spores. Appl Environ Microbiol 75:2936-2939.

Razzell, W.E. and Trussell, P.C. (1963) Isolation and properties of an iron-oxidizing Thiobacillus. J Bacteriol 85:595-603.

Reid, I.N., Sparks, W.B., Lubow, S., Mcgrath, M., Livio, M., Valenti, J., Sowers, K.R., Shukla, H.D., Macauley, S., Miller, T., Suvanasuthi, R., Belas, R., Colman, A., Robb, F.T., Dassarma, P., Müller, J.A., Coker, J.A., Cavicchioli, R., Chen, F., and Dassarma, S. (2006) Terrestrial models for extraterrestrial life: methanogens and halophiles at Martian temperatures. Int J Astrobiol 5:89-97.

Resnick, M.A. (1978) Similar responses to ionizing radiation of fungal and vertebrate cells and the importance of DNA doublestrand breaks. J Theor Biol 71:339-346.

Rettberg, P., Fritze, D., Verbarg, S., Nellen, J., Horneck, G., Stackebrandt, E., and Kminek, G. (2006) Determination of the microbial diversity of spacecraft assembly, testing and launch facilities: first results of the ESA project MiDiv. $A d v$ Space Res 38:1260-1265.

Rettberg, P., Anesio, A., Baker, V., Baross, J.A., Cady, S.L., Foreman, C.M., Hauber, E., Ori, G.B., Pearce, D., Renno, N., Ruvkun, G., Sattler, B., Saunders, M.P., Wagner, D., and Westall, F. (2015) Review of the MEPAG Report on Mars Special Regions. National Academy Press, Washington, DC. Rettberg, P., Anesio, A.M., Baker, V.R., Baross, J.A., Cady, S.L., Detsis, E., Foreman, C., Hauber, E., Ori, G.B., Pearc, D.A., Renno, N.O., Ruvkun, G., Sattler, B., Saunders, M.P., Smith, D.H., Wagner, D., and Westall, F. (2016) Planetary protection and mars special regions-a suggestion for updating the definition. Astrobiology 16:1-7.

Robinson, J. and Gibbons, N.E. (1952) The effect of salts on the growth of Micrococcus halodenitrificans n. sp. Can J Bot 30: 147-154.

Rood, J.I. and Cole, S.T. (1991) Molecular genetics and pathogenesis of Clostridium perfringens. Microbiol Rev 55:621648. 
Rowlinson, M.C., LeBourgeois, P., Ward, K., Song, Y., Finegold, S.M., and Bruckner, D.A. (2006) Isolation of a strictly anaerobic strain of Staphylococcus epidermidis. J Clin Microbiol 44:857-860.

Rummel, J.D., Beaty, D.W., Jones, M.A., Bakermans, C., Barlow, N.G., Boston, P.J., Chevrier, V.F., Clark, B.C., de Vera, J.P.P., Gough, R.V., Hallsworth, J.E., Head, J.W., Hipkin, V.J., Kieft, T.L., Mcewen, A.S., Mellon, M.T., Mikucki, J.A., Nicholson, W.L., Omelon, C.R., Peterson, R., Roden, E.E., Sherwood Lollar, B., Tanaka, K.L., Viola, D., and Wray, J.J. (2014) A new analysis of Mars "special regions": findings of the Second MEPAG Special Regions Science Analysis Group (SR-SAG2). Astrobiology 14:887-968.

Satomi, M., La Duc, M.T., and Venkateswaran, K. (2006) Bacillus safensis sp. nov., isolated from spacecraft and assemblyfacility surfaces. Int J Syst Evol Microbiol 56:1735-1740.

Schenk, P.M. and Turtle, E.P. (2009) Europa's impact craters: probes of the icy shell. In Europa, edited by R.T. Pappalardo, W.B. McKinnon, and K. Khurana, University of Arizona Press, Tucson, pp. 181-198.

Schneegurt, M.A. (2012) Media and conditions for the growth of halophilic and halotolerant bacteria and archaea. In: Advances in Understanding the Biology of Halophilic Microorganisms, edited by R.R. Vreeland, Springer Science+Business Media, Dortrecht.

Schwadron, N.A., Allegrini, F., Bzowski, M., Christian, E.R., Dayeh, M.A., Desai, M.I., Fairchild, K., Frisch, P.C., Funsten, H.O., Fuselier, S.A., Galli, A., Janzen, P., Kubiak, M.A., McComas, D.J., Moebius, E., Reisenfeld, D.B., Sokol, J.M., Swaczyna, P., Szalay, J.R., Wurz, P., and Zirnstein, E.J. (2018) Time dependence of the IBEX ribbon and the globally distributed energetic neutral atom flux using the first 9 years of observations. Astrophys J Suppl Ser 239:17 pp.

Segers, P. Vancanneyt, M., Pot, B., Torck, U., Hoste, B., Dewettnick, D., Falsen, E., Kersters, K., and De Vos, P. (1994) Classification of Pseudomonas diminuta Leifson and Hugh 1954 and Pseudomonas vesicularis Büsing, Döll, and Freytag 1953 in Brevundimonas gen. nov. as Brevundimonas diminuta comb. nov. and Brevundimonas vesicularis comb. nov., respectively. Int J Syst Bacteriol 44:499-510.

Sephton, M.A. (2004) Origin of life. In An Introduction to Astrobiology, edited by I. Gilmour and M.A. Sephtons, Cambridge University Press, Cambridge, pp. 1-41.

Sharma, A., Scott, J.H., Cody, G.D., Fogel, M.L., Hazen, R.M., Hemley, R.J., and Huntress, W.T. (2002) Microbial activity at gigapascal pressures. Science 295:1514-1516.

Smith, S.A., Bernardini III, J.N., Anderl, D., Ford, M., Wear, E., Schrader, M., Schubet, W., DeVeaux, L., Paszczynski, A., and Childers, S.E. (2017) Identification and characterization of early mission phase microorganisms residing on the Mars Science Laboratory and assessment of their potential to survive Mars-like conditions. Astrobiology 17:253-265.

Sogin, M.L., Collins, G., Baker, A., Baross, J.A., Barr, A., Boynton, W.V., Cockell, C.S., Daly, M.J., Fragola, J.A., Lopes, R.M.C., Nealson, K.H., Stetson, D.S., and Thiemens, M.H. (2012) Assessment of Planetary Protection Requirements for Spacecraft Missions to Icy Solar System Bodies. National Academies Press, Washington, DC.

Spencer, J., Tamppari, L.K., Martin, T.Z., and Travis, L.D. (1999) Temperatures on Europa from Galileo photopolarimeter-radiometer: nighttime thermal anomalies. Science 284:1514-1516.

Spencer, J.R. and Nimmo, F. (2013) Enceladus: an active ice world in the Saturn system. Annu Rev Earth Planet Sci 41: 693-717.
Stan-Lotter, H. and Fendrihan, S. (2015) Halophilic Archaea: life with desiccation, radiation and oligotrophy over geological times. Life 5:1487-1496.

Stevenson, A., Cray, J.A., Williams, J.P., Santos, R., Sahay, R., Neuenkirchen, N., Mcclure, C.D., Grant, I.R., Houghton, J.D., Quinn, J.P., Timson, D.J., Patil, S.V., Singhal, R.S., Anton, J., Dijksterhuis, J., Hocking, A.D., Lievens, B., Rangel, D.E., Voytek, M.A., Gunde-Cimerman, N., Oren, A., Timmis, K.N., Mcgenity, T.J., and Hallsworth, J.E. (2015) Is there a common water-activity limit for the three domains of life? ISME J 9:1333-1351.

Stewart, E.J. (2012) Growing unculturable bacteria. J Bacteriol 194:4151-4160.

Stiegelmeier, M., Wirth, R., Kminek, G., and Moissl-Eichinger, C. (2009) Cultivation of anaerobic and facultatively anaerobic bacteria from spacecraft-associated clean rooms. Appl Environ Microbiol 75:3484-3491.

Stieglmeier, M., Rettberg, P., Barczyk, S., Bohmeier, M., Pukall, R., Wirth, R., and Moissl-Eichinger, C. (2012) Abundance and diversity of microbial inhabitants in European spacecraft-associated clean rooms. Astrobiology 12: 572-585.

Tennen, L.I. (2004) Evolution of the planetary protection policy: conflict of science and jurisprudence? Adv Space Res 34: 2354-2362.

Tirumalai, M.R., Rastogi, R., Zamani, N., O’Bryant Williams, E., Allen, S., Diouf, F., Kwende, S., Weinstock, G.M., Venkateswaran, K.J., and Fox, G.E. (2013) Candidate genes that may be responsible for the unusual resistances exhibited by Bacillus pumilus SAFR-032 spores. PLoS One 86:e66012.

Tuovinen, O.H. and Kelly, D.P. (1973) Studies on the growth of Thiobacillus ferrooxidans. Arch Microbiol 88:285-298.

Tyler, R.H. (2008) Strong ocean tidal flow and heating on moons of the outer planets. Nature 456:770-773.

Vaishampayan, P., Osman, S., Andersen, G., and Venkateswaran, K. (2010) High density 16S microarray and clone library-based microbial community composition of the Phoenix spacecraft assembly clean room. Astrobiology 10:499-508.

Vaishampayan, P., Moissl-Eichinger, C., Pukall, R., Schumann, P., Spröer, C., Augustus, A., Roberts, A.H., Namba, G., Cisneros, J., Salmassi, T., and Venkateswaran, K. (2013a) Description of Tersicoccus phoenicis gen. nov., sp. nov. isolated from spacecraft assembly clean room environments. Int J Syst Evol Microbiol 63:2463-2471.

Vaishampayan, P., Probst, A.J., La Duc, M.T., Bargoma, E., Benardini, J.N., Andersen, G.L, and Venkateswaran, K. (2013b) New perspective on viable microbial communities in low-biomass cleanroom environments. ISME J 7:312-324.

Vaishampayan, P., Roberts A.H., Augustus, A., Pukall, R., Schumann, P., Schwendner, P., Mayilraj, S., Salmassi, T., and Venkateswaran, K. (2014) Deinococcus phoenicis sp. nov., an extreme ionizing-radiation-resistant bacterium isolated from the Phoenix Lander assembly facility. ISME J 64:3441-3446.

Vance, S. and Goodman J. (2009) Oceanography of an icecovered moon. In Europa, edited by R.T. Pappalardo, W.B. McKinnon, and K. Khurana, University of Arizona Press, Tucson, USA, pp. 459-482.

Venkateswaran, K., Satomi, M., Chung, S., Kern, R., Koukol, R., Basic, C., and White, D. (2001) Molecular microbial diversity of a spacecraft assembly facility. Syst Appl Microbiol 24:311-320.

Venkateswaran, K., Hattori, N., La Duc, M.T., and Kern, R. (2003a) ATP as a biomarker of viable microorganisms in clean-room facilities. J Microbiol Methods 52:367-377. 
Venkateswaran, K., Kempf, M., Chen, F., Satomi, M., Nicholson, W., and Kern, R. (2003b) Bacillus nealsonii sp. nov., isolated from a spacecraft-assembly facility, whose spores are $\gamma$-radiation resistant. Int J Syst Evol Microbiol 53: $165-172$.

Venkateswaran, K., Vaishampayan, P., Benardini, J.N., Rooney, A.P., and Spry, J.A. (2014) Deposition of extremotolerant bacterial strains isolated during different phases of Phoenix Spacecraft assembly in a public culture collection. Astrobiology 14:24-26.

Waite, J.H., Glein, C.R., Perryman, R.S., Teolis, B.D., Magee, B.A., Miller, G., Grimes, J., Perry, M.E., Bouquet, A., Lunine, J.I., Brockwell, T., and Bolton, S.J. (2017) Cassini finds molecular hydrogen in the Enceladus plume: evidence for hydrothermal processes. Science 356:155-159.

Winans, L., Pflug, I.J., and Foster, T.L. (1977) Dry-heat resistance of selected psychrophiles. Appl Environ Microbiol 34: 150-154.

Zeitlin, C., Hassler, D.M., Cucinotta, F.A., Ehresmann, B., Wimmer-Schweingruber, R.F., Brinza, D.E., Kang, S., Weigle, G., Böttcher, S., Böhm, E., Burmeister, S., Guo, J., Köhler, J., Martin, C., Posner, A., Rafkin, S., and Reitz, G. (2013) Measurements of energetic particle radiation in transit to mars on the Mars Science Laboratory. Science 2013:1080-1084.

Zhai, M., Sulloway, H.M., Scholten, J.C., Brown, M.G., Balkwill, D.L., and Daly., M.J. (2008) Protein oxidation: key to bacterial desiccation resistance? ISME J 2:393-403.

Zhang, W., Li, F., and Nie, L. (2010) Integrating multiple 'omics' analysis for microbial biology: application and methodologies. Microbiology 156:287-301.

Zhang, Y., Xin, C., Wang, X., and Deng, Y. (2018) Detection of microorganism from China's spacecraft assembly cleanroom. Acta Astronaut 18.

\section{Appendix 1}

The Planetary Protection of Outer Solar System consortium (http://pposs.org/)

- German Aerospace Center (DLR), Köln, GermanyPetra Rettberg, Stefan Leuko, Elke Rabbow

- Science Connect-European Science Foundation (ESF)_Strasbourg, France (Coordinator) Nicolas Walter, Patricia Cabezas

- Committee of Space Research (COSPAR), Montpellier, France-Jean-Loius Fellous, Alissa Haddaji, Gerhard Kminek

- Eurospace, Paris, France-Jean-Charles Treuet

- Imperial College, London, United Kingdom-Mark Sephton

- National Institute for Astrophysics (INAF), Florence, Italy-John Brucato

- Space Technology Ireland Ltd., Ireleand-Susan McKenna-Lawlor

\section{Expert}

TASI, Italy-Diana Margheritis

International Partner

China Academy of Space Technology, China.

International Observer
Address correspondence to: Petra Rettberg

German Aerospace Center (DLR) Institute of Aerospace Medicine Radiation Biology Department Research Group Astrobiology

Linder Höhe

51147 Köln

Germany

E-mail: petra.rettberg@dlr.de

Submitted 5 December 2018

Accepted 8 January 2019

Associate Editor: Christopher McKay

$\begin{aligned} & \text { Abbreviations Used } \\ \mathrm{ATP}= & \text { adenosine triphosphate } \\ \mathrm{CFUs}= & \text { colony-forming units } \\ \mathrm{COSPAR}= & \text { Committee on Space Research } \\ \mathrm{ECSS}= & \text { European Cooperation for Space } \\ & \text { Standardization } \\ \mathrm{EURECA}= & \text { European Retrievable Carriere } \\ \mathrm{HZE}= & \text { high }(\mathrm{H}) \text { atomic number }(\mathrm{Z}) \text { and } \\ & \text { energy }(\mathrm{E}) \\ \mathrm{LDEF}= & \text { Long Duration Exposure Facility } \\ \mathrm{PMA}= & \text { propidium monoazide } \\ \mathrm{PPOSS}= & \text { Planetary Protection of the Outer Solar } \\ & \text { System } \\ \mathrm{RAD}= & \text { Radiation Assessment Detector }\end{aligned}$

Office of the Space Studies Board of the National Research Council office, USA

\section{Appendix 2}

Participants of the Biological and Organic Contamination Prevention Workshops, January 23-27, 2017 at DLR in Köln, Germany, and April 10-12, 2017 at INAF in Firenze, Italy.

André Antunes Edge Hill University, United Kingdom Berger, Thomas DLR, Germany

Canham, John Orbital ATK, USA

Collins, Geoffrey Wheaton College, USA

Cullen, David Cranfield University, United Kingdom Dworkin, Jason GSFC, USA

Francis, Karen Olson The Open University, United Kingdom

Funke, Oliver DLR, Germany

Grasset, Olivier Nantes University, France

Horneck, Gerda DLR, Germany

Margheritis, Diana TASI, Italy

Marteinsson, Vigo Matis, Iceland

Martin, Willliam University of Düsseldorf, Germany

Pearce, David Northumbria University, United Kingdom 
Pearson, Victoria The Open University, United Kingdom Raulin, Francois LISA/UPEC-CNRS, France

Saunders, Mark Independent consultant for the National Academies of Sciences (NAS), USA

Scharge, Yvonne Max Plank Institute for Solar System Research, Germany
Spry, Andy SETI, USA

Smith, David Space Studies Board, USA

Steininger, Harald Max Plank Institute for Solar System Research, Germany

Watson, Jonathan IC, United Kingdom

Yano, Hajime ISAS/JAXA, Japan 